\title{
Thermal tides and studies to tune the mechanistic tidal model using UARS observations
}

\author{
V. A. Yudin ${ }^{1}$, B. V. Khattatov ${ }^{2}$, M. A. Geller ${ }^{1}$, D. A. Ortland ${ }^{3}$, C. McLandress ${ }^{4}$, G. G. Shepherd ${ }^{5}$ \\ ${ }^{1}$ Institute for Terrestrial and Planetary Atmospheres, State University of New York at Stony Brook, Stony Brook, NY 11794-5000, USA \\ 2 National Center for Atmospheric Research, Boulder, Colorado, P.O. Box 300, USA \\ ${ }^{3}$ Space Physics Research Laboratory, University of Michigan, Ann Arbor, MI 48109, USA \\ ${ }^{4}$ Institute for Space and Terrestrial Science, York University, Ontario, M3J 1P3, Canada \\ ${ }^{5}$ Centre for Research in Earth and Space Science, York University, Ontario, M3J 1P3, Canada
}

Received: 28 October 1996 / Revised: 2 June 1997 / Accepted 2 July 1997

\begin{abstract}
Monthly simulations of the thermal diurnal and semidiurnal tides are compared to High-Resolution Doppler Imager (HRDI) and Wind Imaging Interferometer (WINDII) wind and temperature measurements on the Upper-Atmosphere Research Satellite (UARS). There is encouraging agreement between the observations and the linear global mechanistic tidal model results both for the diurnal and semidiurnal components in the equatorial and mid-latitude regions. This gives us the confidence to outline the first steps of an assimilative analysis/interpretation for tides, dissipation, and mean flow using a combination of model results and the global measurements from HRDI and WINDII. The sensitivity of the proposed technique to the initial guess employed to obtain a best fit to the data by tuning model parameters is discussed for the January and March 1993 cases, when the WINDII day and night measurements of the meridional winds between 90 and $110 \mathrm{~km}$ are used along with the daytime HRDI measurements. Several examples for the derivation of the tidal variables and decomposition of the measured winds into tidal and mean flow components using this approach are compared with previous tidal estimates and modeling results for the migrating tides. The seasonal cycle of the derived diurnal tidal amplitudes are discussed and compared with radar observation between 80 and $100 \mathrm{~km}$ and $40^{\circ} \mathrm{S}$ and $40^{\circ} \mathrm{N}$.
\end{abstract}

\section{Introduction}

The diurnal and semidiurnal tides in the mesosphere and lower thermosphere (MLT) have been studied for several decades, basically through analyses of winds and temperatures by ground-based instruments (radars, lidars, and optical interferometers). Recently, space

Correspondence to: V. A. Yudin e-mail: vyudin@uars.sunysb.edu studies have been successfully used to show the global tidal signatures from satellite wind measurements in the MLT region (Hays et al., 1994; Burrage et al., 1995a, b; McLandress et al., 1996a). The High-Resolution Doppler Imager (HRDI) is one of wind and temperature measuring instruments on the Upper-Atmosphere Research Satellite (UARS) (Hays et al., 1993; Ortland et al., 1995). HRDI has been monitoring the MLT region (50$115 \mathrm{~km}$ ) since November 1991, and extensive comparisons of its wind product with ground-based measurements (MF and meteor radars, rockets, etc.), as well as with the wind structures observed by the Wind Imaging Interferometer (WINDII, also on board UARS) have been presented by Burrage et al. (1996), Khattatov et al., (1996), and McLandress et al. (1996b). These comparisons show an excellent agreement between these two satellite databases in the lower thermosphere where overlapping regions of HRDI and WINDII observations exist.

There are several reasons for studying thermal tides using the combination of the UARS wind, temperature, constituent observations, and model simulations:

1. The HRDI/WINDII wind and temperature measurements give the first long-term information on the global wave structures and circulation that help to constrain "open" model parameters in the MLT region.

2. In the region where the tidal signal is dominant we need to filter out the daily varying components from data to obtain reliable estimates for the mean flow and other low-frequency global waves.

3. Stratospheric ozone and temperature measured by other UARS instruments give an opportunity to estimate the ozone tidal forcing and validate the tidal temperature oscillations simulated by models in the stratosphere.

4. Despite the qualitative agreement between the tidal models and HRDI/WINDII observations of tides noted by Burrage et al. (1995a), McLandress et al., (1996a), and Hagan et al. (1997), there are still quantitative differences between them. 
Taking into account that the UARS wind composites for tidal studies have usually been obtained by collection of observations over a month, it is clear that the presence of gravity waves, planetary waves, and a timevarying mean flow may result in a significant aliasing for the direct extraction of tides from the measured zonal wind and temperature fields (McLandress et al., 1996a). In that sense, the developing of a tidal model that gives results closely matching the observed satellite tidal signatures is a beneficial step toward assimilative interpretation of the UARS MLT wind and temperature measurements.

In previous papers by Khattatov et al. (1997a,b), a relatively simple and effective technique for the analysis of diurnal migrating tidal structures observed by HRDI has been developed. The daytime HRDI monthly meridional $(\mathrm{V})$ wind data were used in those papers to retrieve the diurnal tidal variables and implied tidal dissipation, parameterized as a Rayleigh friction coefficient using the combined adjustments of the HRDI V diurnal winds around the equator and the modeled amplitudes where the HRDI V winds show profound diurnal oscillations between about $10^{\circ}$ and $40^{\circ}$ (north and south). The assumption that the average of the HRDI V winds over all available local times reflects only the diurnal tidal signatures was a basic criterion for the adjustment of the simulated $\mathrm{V}$ diurnal amplitudes to the HRDI V wind observations in Khattatov et al. (1997a). This criterion seems to give an artificial increase in the diurnal wind amplitudes, due to the residual signatures of the semidiurnal $\mathrm{V}$ winds, after calculation of the local-time-averaged HRDI winds above $90 \mathrm{~km}$. To find out how serious this limitation is for our model tuning, we employed the day- and nighttime WINDII wind observations between 90 and $110 \mathrm{~km}$ together with the daytime HRDI winds below $90 \mathrm{~km}$ (McLandress et al., 1996b).

The technique developed by Khattatov et al. (1997b) was based on an "inviscid" numerical model that also used some simplification of tidal equations. One of them is a Rayleigh treatment of tidal dissipation. This approximation cannot simulate correctly the semidiurnal tide above $90 \mathrm{~km}$ and also has some limitations for modeling of the diurnal oscillations in the region where damping of the diurnal tide is significant. For these reasons, we develop a "viscid" mechanistic tidal model that is similar in its basic numerical aspects and mathematical treatment of tidal dissipation to the Global-Scale Wave Model (GSWM) of Hagan et al. (1995).

The main subject of this paper is to show how we can tune the tidal model to UARS observations of the diurnal and semidiurnal tides and outline possible procedures for assimilative interpretation of HRDI/ WINDII wind measurements using the tuned mechanistic tidal model (TMTM) methodology in the MLT region. In its major aspects, the TMTM is similar in numerical formulation to the GSWM of Hagan et al. (1995), except that the satellite wind data are used for the evaluation of tidal dissipation, which is a poorly known model parameter. In a number of tidal simula- tions, we also use the Microwave Limb Sounder (MLS) ozone observations (Ricaud et al., 1996) for calculations of the ozone tidal forcing in the stratosphere and mesosphere.

Section 2 provides a brief review of the HRDI/ WINDII wind data for tidal studies. We also show that our tidal model, without any tuning, can reproduce the basic features of the satellite observed winds. A brief model description and general aspects of the model tuning will be described in Sect. 3 and the Appendix. In Sect. 4, we present results for the diurnal and semidiurnal tides as seen by HRDI/WINDII and simulated by the TMTM. Comparisons of the seasonal variation of the derived dissipation and diurnal amplitudes with the available radar climatology and other modeling results are also discussed. Section 5 presents our summary and conclusions.

\section{HRDI and WINDII wind data sets for tidal studies}

The HRDI instrument has been described in detail by Hays et al., (1993), and interested readers are referred there for more details. During the day, the horizontal wind components are determined from Doppler shifts in the molecular oxygen $(0,0)$ atmospheric band emission lines over the altitude range $50-120 \mathrm{~km}$. WINDII observes winds and volume emission rates in the 90$300-\mathrm{km}$ height region by measuring the Doppler shift of emission lines of different species (Shepherd et al., 1993). Several papers concerning thermal tides observed from WINDII have been published using the data from the green-line emission (McLandress et al., 1996a; Hagan et al., 1997; Akmaev et al., 1997). A beneficial feature of this emission for tidal studies is that it gives $24 \mathrm{~h}$ of local-time coverage between 90 and $110 \mathrm{~km}$. The horizontal resolution of the HRDI/WINDII sampling is about $500 \mathrm{~km}$ and the vertical resolution is approximately $3 \mathrm{~km}$. Due to the orbital inclination of the UARS spacecraft, the maximum latitude coverage observed is about $74^{\circ}$ in one hemisphere and $42^{\circ}$ in the other. The precession of the UARS orbit provides a coverage of all local times in about 36 days (Burrage et al., 1995b). Under these conditions, HRDI and WINDII are able to supply data for tidal analysis by collecting observations over a month.

Version 8 of the level 3AT HRDI data has been used in this study for the analysis of the seasonal variability of the diurnal tide in the MLT region. To check the repeatability of the tidal signatures in the 1992-1994 HRDI monthly mean wind composites, we analyzed the daytime averages of the root-mean-square (rms) zonal and meridional wind. As a first approximation, the daytime averages of the rms winds are proportional to the kinetic energy of the fluctuating motions and give us a condensed quick look at the distribution of the tidal kinetic energy. From the rms wind analysis, we found that the 1992-1993 monthly mean HRDI composites have similar patterns and locations of tidal-wind energy concentration. The 1994 wind rms showed a much weaker concentration of kinetic energy in the low- 
latitudinal MLT region. Such attenuation of the $(1,1)$ mode diurnal amplitudes after September 1993 has been previously reported by Burrage et al. (1995a). Given the level of interannual variability for the diurnal oscillations, we decided to use only the 1992-1993 HRDI monthly mean wind composites in this study. As an independent check of our techniques to extract the diurnal tide from the daytime HRDI data, we utilize the published results for estimates of diurnal amplitudes and phases from the 1992-1993 WINDII green-line observation (McLandress et al., 1996a), as well as the combined HRDI/WINDII data set around March and January 1993 (McLandress et al., 1996b). For a given month, the HRDI and WINDII data was accumulated and binned on a regular grid in local time and latitude. Bins of 1-h local time and $5^{\circ}$ latitude have been used.

The same gridding of the 95-km HRDI observations has been used by Burrage et al. (1995b) to constrain a 2year morphology of the semidiurnal tide. Despite the 24-h coverage at this level, Burrage et al. (1995b) emphasized that due to the geophysical variance associated with the monthly composites of HRDI data, the retrieved semidiurnal amplitudes are subject to an uncertainty of about $10 \mathrm{~m} / \mathrm{s}$. The quantitative analysis of HRDI measurements is made more difficult for other altitudes because the average local-time coverage of the data during a month is on the order of $8-15 \mathrm{~h}$. The traditional method to extract tidal information from geophysical data set is to use a least-squares fit to data. Based on modeling predictions Hays et al. (1994) have also utilized the horizontal behavior of the diurnal tide and fitted the HRDI V wind to the $(1,1)$ Hough wind expansion function. Shortcomings of this approach are that: (1) it considers only one symmetric tidal mode; (2) such a fitting procedure does not cover latitudes greater than $30^{\circ}$ and altitudes above $90 \mathrm{~km}$ where the superposition of diurnal and semidiurnal tides determines the HRDI wind structures.

Figure 1 illustrates the meridional asymmetry of tides using a comparison of the HRDI V winds in March 1993 with our mechanistic tidal model simulations (March) at 12 LT. The first row of Fig. 1 illustrates separate model predictions of the diurnal and semidiurnal migrating tides. The bottom row shows a superposition of the modeled diurnal and semidiurnal oscillations (left plot) and the monthly mean HRDI V wind observations (right plot). It is clearly seen that the semidiurnal tide predicted by the model is an important component of the meridional wind above $95 \mathrm{~km}$ even in the low-latitude MLT region. A similar comparison for zonal winds is illustrated by Fig. 2. For these simulations, we used the monthly mean background zonal wind and temperature from the MSISE-90 and HWM93 empirical models (Hedin, 1991; Hedin et al., 1993) and a latitude-independent eddy dissipation below $110 \mathrm{~km}$ which allows us to simulate the diurnal amplitude maximum position around $95 \mathrm{~km}$.

From these model/data comparisons (Figs. 1 and 2) we conclude that without additional tuning our model results reproduce the basic tidal features observed by HRDI, in particular, the wind sign changes with height.
Good agreement between the diurnal phases simulated by the model and retrieved by the least-squares fit (LSF) procedures to the HRDI V-winds have been reported by Khattatov et al. (1997a). The present simulations show that in the case of semidiurnal oscillation, the modeled and observed winds have a reasonable agreement above $90 \mathrm{~km}$. However, there are differences in magnitudes between the simulated tides and the observed winds. These discrepancies may be attributable to inaccuracies in the model parameters, such as a tidal dissipation, background temperature, zonal wind, and tidal forcing. In what follows we describe a methodology that allows us to use the global coverage of the UARS wind data in the model to retrieve some information about the tidal dissipation and background zonal wind in the region where tides are the dominant motions.

\section{Model description and tuning procedures}

The numerical model used in this study is a stationary linear model for migrating thermal tides in geometric height coordinates from the surface to $300 \mathrm{~km}$ with a $2-\mathrm{km}$ vertical step and a horizontal resolution of $2^{\circ}$ from pole to pole. This model is similar in its basic aspects of mathematical formulation to the GSWM described by Hagan et al. (1995). In the MLT region, the model dissipation is described only by conductivity and viscosity terms, without radiative damping. Before tuning to the satellite data, the model employs a latitude-independent vertical profile of eddy dissipation with Prandtl number equal to 1 that crudely matches the position of the meridional wind amplitude maxima between 90 and $100 \mathrm{~km}$, as observed. The monthly mean molecular conductivity and viscosity coefficients are calculated using the composition and temperature from the MSISE-90 empirical model (Hedin, 1991). The background temperature and wind fields were taken from MSISE-90 and HWM-93 empirical models (Hedin, 1991, Hedin et al. 1993). For calculation of the tidal forcing, we use heating parameterizations similar to those used by Hagan et al. (1995) in the stratosphere and the MLT region, and by Khattatov et al. (1997a) in the troposphere except for the input data for the monthly averaged ozone and water-vapor densities.

To be more consistent with the UARS observations and the a priori climatological inputs that are used in the retrievals of UARS ozone and water-vapor measurements, we used the UARS reference climatology to give the monthly and zonally averaged densities of ozone and water vapor (Grose and Gille, 1996). In a number of other numerical simulations of tides, we also derived the monthly averaged ozone fields using the MLS ozone observations between 20 and $75 \mathrm{~km}$ (Froidevaux et al., 1996; Ricaud et al., 1996). MLS data was collected 2 weeks before and 2 weeks after the execution of the yaw maneuver to constrain the pole-to-pole global ozone distribution. We did not consider the effects of the observed diurnal variations of ozone in the upper stratosphere and mesosphere as discussed by Ricaud et al. (1996). To derive the zonally averaged monthly 

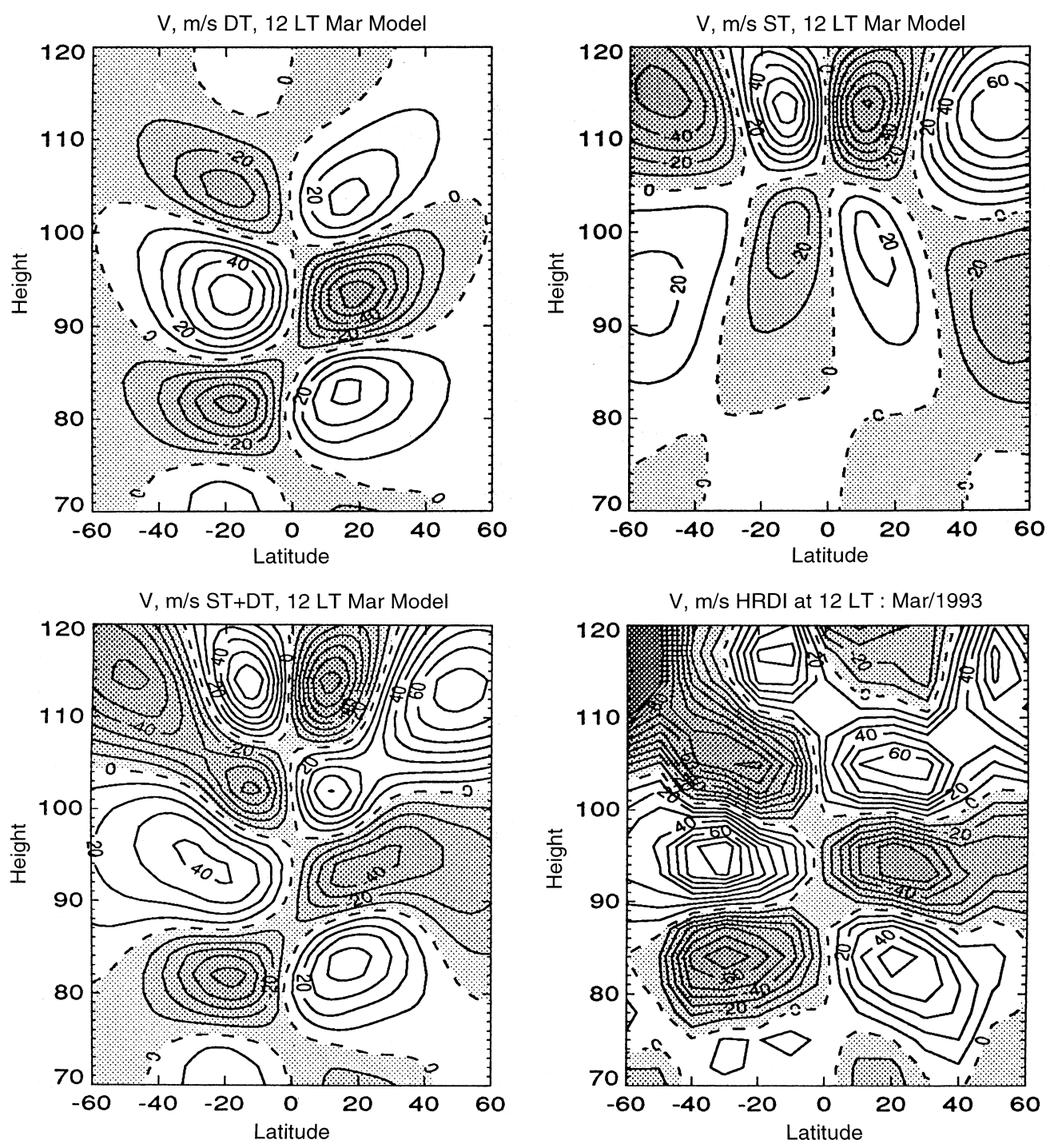

Fig. 1. Meridional winds predicted by mechanistic tidal model results (without tuning) for March, and the HRDI meridional wind observations for March 1993 at 12 LT. Southward winds are shaded; dashed contour is the zero wind line

mean ozone densities, the collected MLS ozone data was binned in local solar time, altitude and height for each 4-week period and averaged over all available local solar times. Such procedures were used for the calculation of the ozone tidal forcing for July/August, March/April 1993, and December/January 1992/93.

Khattatov et al. (1997a,b) developed a strategy for estimating the tidal damping using an inviscid model for the diurnal tide and daytime HRDI meridional wind observations. Their results showed profound seasonal changes in the estimated diurnal tidal amplitudes and dissipation. As emphasized also by Burrage et al. (1995), Hagan et al. (1997) and discussed by Akmaev et al. (1997), Geller et al. (1997) through models/measurements comparisons, the observed strong seasonal variability of the UARS tidal winds cannot be fully explained by the seasonal variations of tidal forcing and the background temperatures and winds, employed or generated by the models.

Following these results, our first possible goal is to tune the tidal damping. The basic idea is to use reliable estimates of the $\mathrm{V}$ tidal amplitudes obtained by the LSF to the UARS wind data in the model equations and calculate the tidal damping and the rest of tidal variables that are consistent with these estimates and the other prescribed model parameters (e.g., tidal forcing, background temperatures and winds). Realization of this strategy has been described by Khattatov et al. (1997b) for the analysis of the HRDI diurnal tidal winds using the inviscid tidal model and iterative numerical scheme for estimation of the Rayleigh friction coefficient as a parameter describing the tidal dissipation in their model. The Rayleigh friction treatment for tidal dissipation cannot simulate correctly the semidiurnal tide and also has some limitations for the modeling of the diurnal tide in the lower thermosphere (see also the discussion in Forbes and Vial, 1991).

We now consider the basic steps of tuning the present viscid tidal model to the HRDI/WINDII tidal winds, leaving the mathematical details of the tidal damping (vertical diffusivity) estimation to the Appendix and using the general approach described by Khattatov et al. (1997b) for the iterative estimation of the other tidal variables and dissipation. For more details the interested 

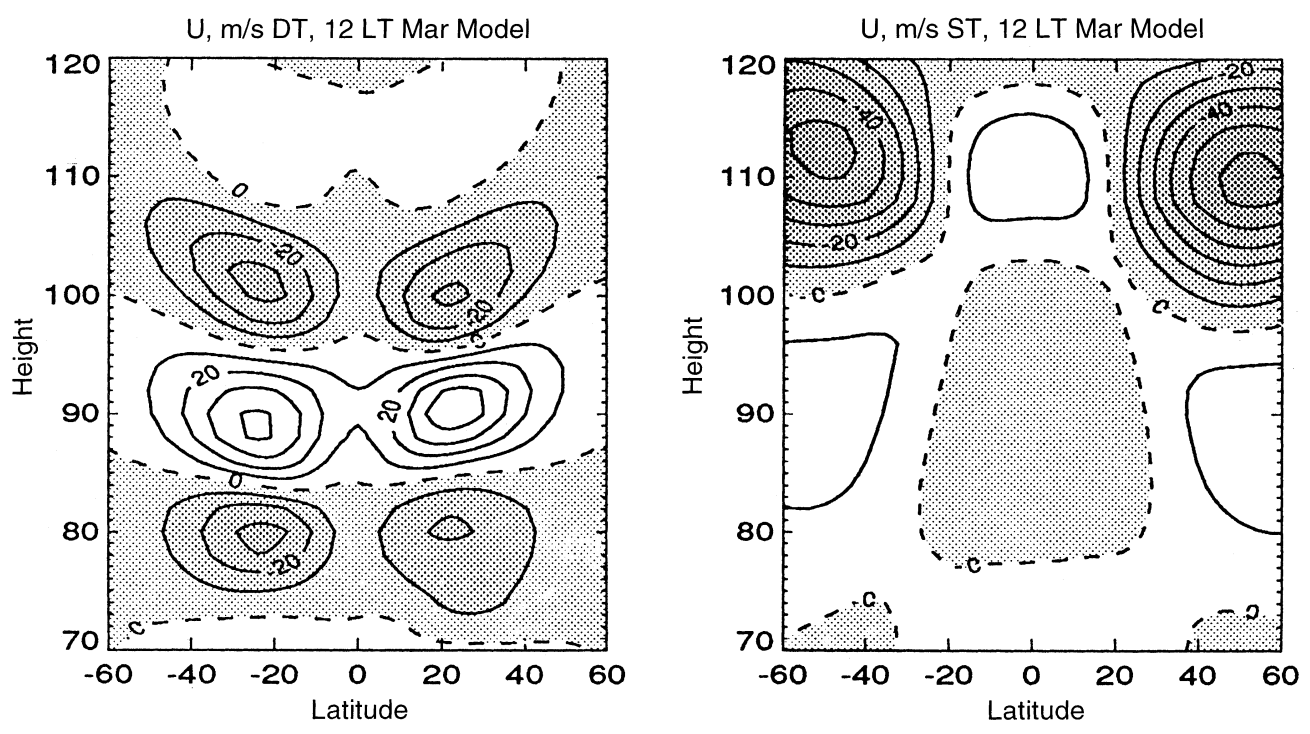

$\mathrm{U}, \mathrm{m} / \mathrm{s} \mathrm{ST}+\mathrm{DT}+\mathrm{UO}, 12 \mathrm{LT}$ Mar Model

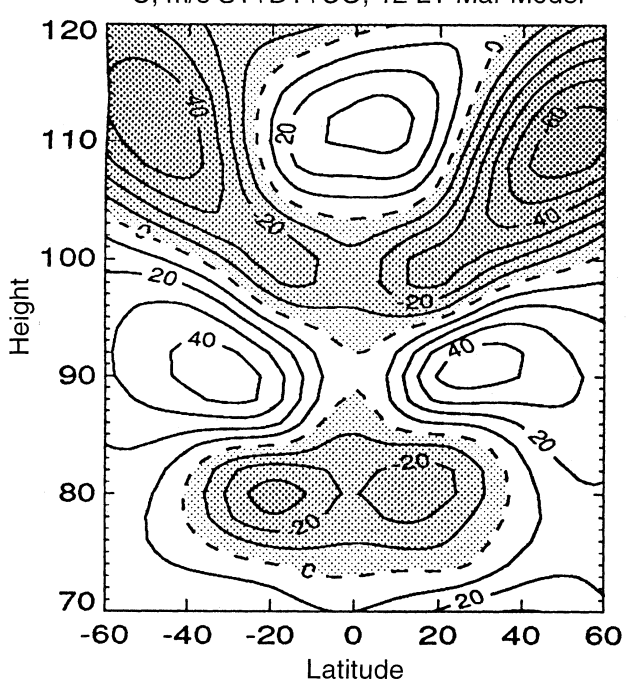

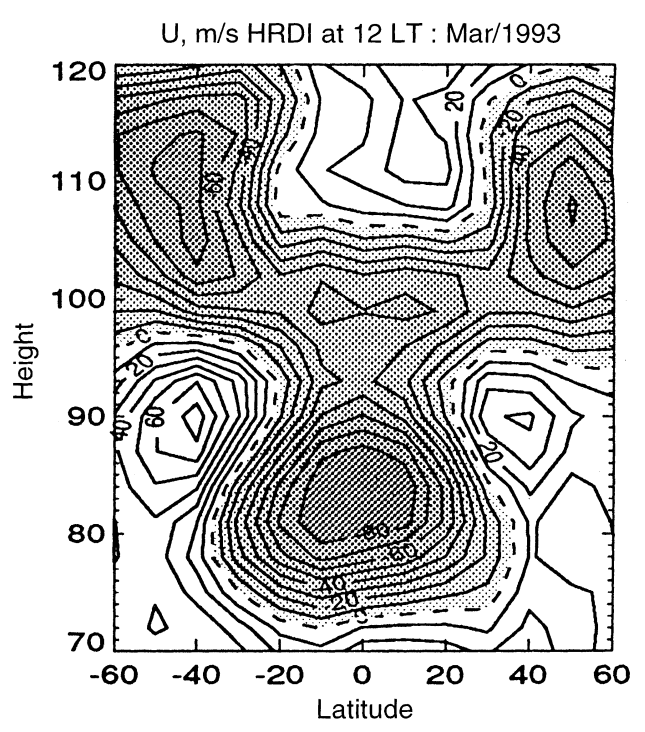

Fig. 2. Zonal winds predicted by mechanistic tidal model results (without tuning), HWM-93 zonal mean wind for March, and HRDI zonal wind observations for March 1993 at 12 LT. Westward winds are shaded; dashed contour is the zero wind line reader is referred to the subsection "Strategy" in Khattatov et al. (1997b).

1. We run the tidal model for the diurnal and semidiurnal components separately and sample the superposition of the two model solutions to form the HRDI/WINDII monthly mean wind composites. Comparisons between the monthly HRDI/WINDII V winds and model simulations help us to estimate how close the "untuned" model results are to the satellite data (Fig. 1).

2. The modeled diurnal amplitudes of the $\mathrm{V}$ winds are adjusted to match the $\mathrm{V}$ amplitudes derived from the UARS data by the LSF analysis. We correct the latitudinal structure of the model amplitudes as dictated by the LSF diurnal amplitude estimates of the HRDI/ WINDII meridional winds between 80 and $110 \mathrm{~km}$ at each model height. In the case of the 24-h WINDII wind data, the diurnal and semidiurnal tides are separated straightforwardly by a LSF procedure (McLandress et al., 1996a). The daytime coverage of HRDI data is known to be insufficient for reliable decomposition of wind data into the mean, diurnal, and semidiurnal components (Crary and Forbes, 1982). By using a tidal model, we utilize the global latitudinal coverage of HRDI observations as proposed by Khattatov et al. (1997a) for estimates of the diurnal $\mathrm{V}$ amplitudes. The basic differences between the present approach and the Khattatov et al. (1997a) adjustment technique are the following.

a. In the vicinity of the highest level of the HRDI wind observations, we use the vertical shape of the model-predicted diurnal amplitude rather than the LSF amplitude estimates. In this region, the LSF amplitude estimates give incorrect results due to the partial localtime coverage in the HRDI data and the dominant signatures of the semidiurnal tide (Fig. 1). Below $70 \mathrm{~km}$ we also use the model predicted amplitudes due to the significant influence of the prescribed stratospheric ozone forcing. The $70-80 \mathrm{~km}$ and $110-120 \mathrm{~km}$ regions are transition zones between the pure and modified model solutions.

b. Because the phase tuning of the mechanistic tidal model is difficult to design with the prescribed tidal forcing and without a comprehensive description of 
gravity wave-tidal interactions, we use simulated phases. This is justified by the fact that these phases above $70 \mathrm{~km}$ are close to the observed ones in most cases, as seen, for instance, in Fig. 1.

c. Resemblance of the modified model and UARS V winds and a comparison between the tuned model and satellite daytime averages of the rms wind serve as an additional check and criterion for the robustness of the employed amplitude correction. The assumption that the average of the HRDI semidiurnal winds over the available local times (daytime period or less) equals zero was a basic criterion for adjustment of the simulated diurnal $\mathrm{V}$ amplitudes to the HRDI $\mathrm{V}$ winds in Khattatov et al. (1997a). This assumption gives an artificial increase of the diurnal $\mathrm{V}$ amplitudes due to the residual signatures of the semidiurnal tide in the localtime-averaged $\mathrm{Vs}$ above $90 \mathrm{~km}$ at middle latitudes (Fig. 5 in Khattatov et al. 1997a).

Typical examples of the rms meridional wind latitudinal structures of the HRDI/WINDII data, diurnal fits, and model results modified to match the diurnal amplitude fits are shown in Figs. 3 and 4 (March and January 1993). We can see that the modified model amplitudes reasonably approximate the main features of the rms wind distribution between 80 and $110 \mathrm{~km}$ for the equinox and solstice months. The basic differences between the observed and modified model rms magnitudes can probably be attributed to a weakness in applying LSF procedures to the daytime-only wind observations (below $90 \mathrm{~km}$ ), the utilization of a simple tidal model with prescribed climatological inputs, and the neglect of the contribution from other motions (time-varying mean winds, planetary waves, etc.).

3. At this point in the procedure we have several choices to continue our model-data analysis, because one of the tidal variables, V, ( meridional wind) has already been determined and so we can calculate the remaining tidal variables and estimate the tidal damping in the region of the UARS observations, using the tidal equations.

In particular, the calculation of the diurnal and semidiurnal oscillations of the zonal wind and temperature which are consistent with the adjusted $\mathrm{V}$ and other "frozen" model parameters provides a means to remove tidal oscillations from these fields and so analyze the monthly zonally averaged mean fields and their influence on the tidal propagation. Due to the incomplete status of the HRDI MLT temperature data-set processing we have not changed the background wind and temperature fields in the model. Some results of the model sensitivity to the new background zonal winds, constrained by compilation of the HRDI stratospheric and MLT mean zonal winds (the MLT tides were removed from the HRDI winds using the TMTM simulations) and the HWM-93 empirical wind model have been obtained and will be reported elsewhere. Briefly, these preliminary model sensitivity results (not shown) confirmed conclusions presented by Geller et al. (1997) and Akmaev et al. (1997) that the specification of the tidal damping in the MLT region is one of the important issues for the model tuning to UARS observations.
To estimate the tidal dissipation, we use the wave energy equation to calculate the damping needed to reproduce the modified model amplitudes that match the UARS wind data. In the Appendix, we describe an evaluation of the vertical eddy diffusion coefficient for the viscid tidal model formulation.

\section{Results and discussion}

Because of the high sensitivity of diurnal tidal amplitudes in the MLT region to atmospheric dissipation, we first present the TMTM results for the diurnal tidal component for equinox and solstice periods around March 1993 and January 1993. These periods are selected for comparison with the WINDII diurnal tide estimates of McLandress et al. (1996a) in the 90-110 km region, and with the Spectral Mesosphere/Lower Thermosphere Model results (SMLTM) presented by Akmaev et al. (1997). There is generally good agreement between the phase structure of the meridional diurnal tides derived from the UARS observations and predicted by the tidal model without additional tuning (e.g., Figs. 1 and 2 ), but we see significant differences in the diurnal amplitudes. That is why in Figs. 5 and 6 we plot the amplitudes of the diurnal winds and temperatures for different simulations of the TMTM (first two rows) and compare them with the amplitude estimates from the original data using only the LSF procedure (last row). We concentrate on the region between $-40 / 40$ latitudes and $80-110 \mathrm{~km}$ where strong diurnal tidal signatures are observed by HRDI and WINDII and where the additional tuning of the tidal model has been done.

For equinox conditions (Fig. 5), two simulations of the TMTM are presented. The first row corresponds to the TMTM results using the first guess and procedures from Khattatov et al. (1997a), which utilizes only the daytime HRDI meridional winds for the derivation of the amplitudes. The second row is the TMTM results that use the described tuning procedures and the WINDII data between 90 and $110 \mathrm{~km}$ and the HRDI data below $90 \mathrm{~km}$. The difference between the two TMTM simulations is a reflection of the different initial guesses employed. The qualitative similarity of the two results indicates that the basic structure of the meridional wind amplitudes is reasonably well reproduced by the TMTM for the equinox period using only the daytime HRDI observations. Comparison to the WINDII amplitude estimates (bottom row) shows that the TMTM is able to reproduce the latitudinal structure of the observed amplitudes and the positions of amplitude maxima. It is interesting to note that the same shape of the diurnal amplitudes is reproduced by the SMLTM in April (Akmaev et al., 1997) where the eddy diffusion is calculated, depending on the gravity wave deposition rate in their middle-atmosphere general circulation model.

There is poorer agreement between the TMTM runs and the zonal diurnal amplitudes estimated by WINDII (second column of Fig. 5). Although the differences between the TMTM and WINDII zonal wind ampli- 

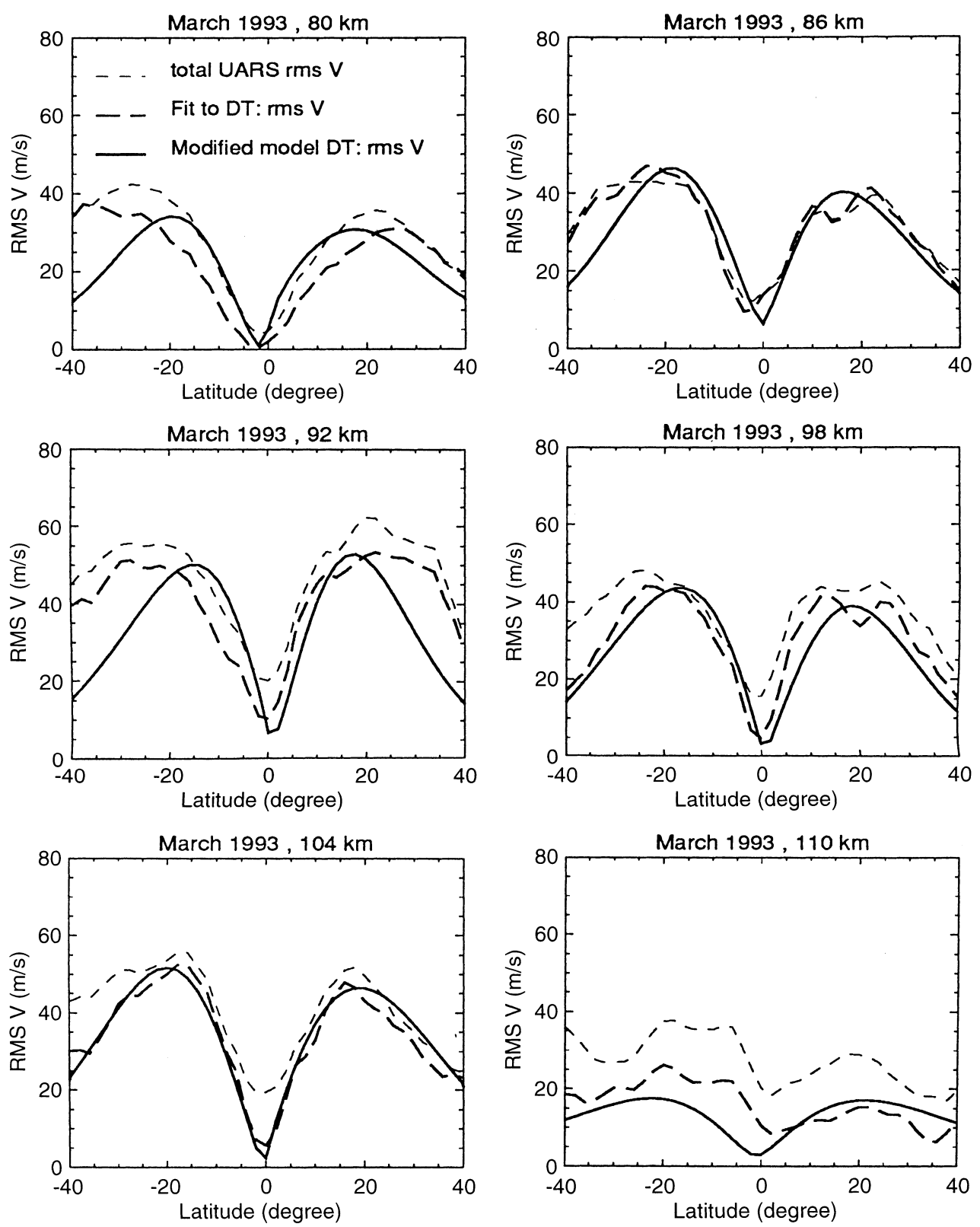

Fig. 3. Latitudinal structures of the RMS meridional (V) winds at different levels for March 1993. The dashed thin line is the total daytime averaged rms HRDI/ WINDII wind; dashed thick line is the diurnal tide rms wind, derived by least-squares fits to observations; the solid line is the rms wind corresponding to the modified $\mathrm{V}$ diurnal amplitudes used in our model tudes are of order $10-15 \mathrm{~m} / \mathrm{s}$, the LSF estimates of the zonal wind amplitudes from WINDII measurements do not resemble the simulated diurnal amplitude shapes as well as we can find for the meridional wind component. There are several possible reasons for this disagreement. First is that there is a significant signal of the nonmigrating diurnal tide in the observed wind, and the TMTM simulation does not reproduce nonmigrating tidal signatures. This possibility is discussed by Hagan et al. (1997) as a possible reason for some larger model/ measurement discrepancies. Another important issue is the difficulty in extracting the diurnal migrating tide from the zonal wind measurements due to variations in the mean zonal flow and the presence of other wave motions (see Forbes et al., 1994; Hays et al., 1994; McLandress et al., 1996a).

As an additional check of the quality of the TMTM prediction, we compare the model-simulated diurnal temperature amplitudes in the equatorial region below $105 \mathrm{~km}$ with the recently available diurnal oscillations in HRDI temperatures (Ortland et al. 1995). Some details of the retrieved HRDI temperature fields and the fitting procedures for deriving tidal amplitudes are briefly discussed in Akmaev et al. (1997). Complete details of the inversion method and validation will be discussed in forthcoming papers. Here, we would like to emphasize the good agreement between TMTM and HRDI observed temperature amplitudes (last column of Fig. 5) in the vicinity of the equator where there are no serious tuning constraints except through the governing tidal equations ( $\mathrm{V}$ wind oscillations are close to zero in the equatorial region). There is also reasonable agreement of the diurnal zonal wind and temperature amplitudes between the TMTM and the SMLTM (Figs. 1-3 in Akmaev et al., 1997) for the equinox periods. Some quantitative distinction between these 

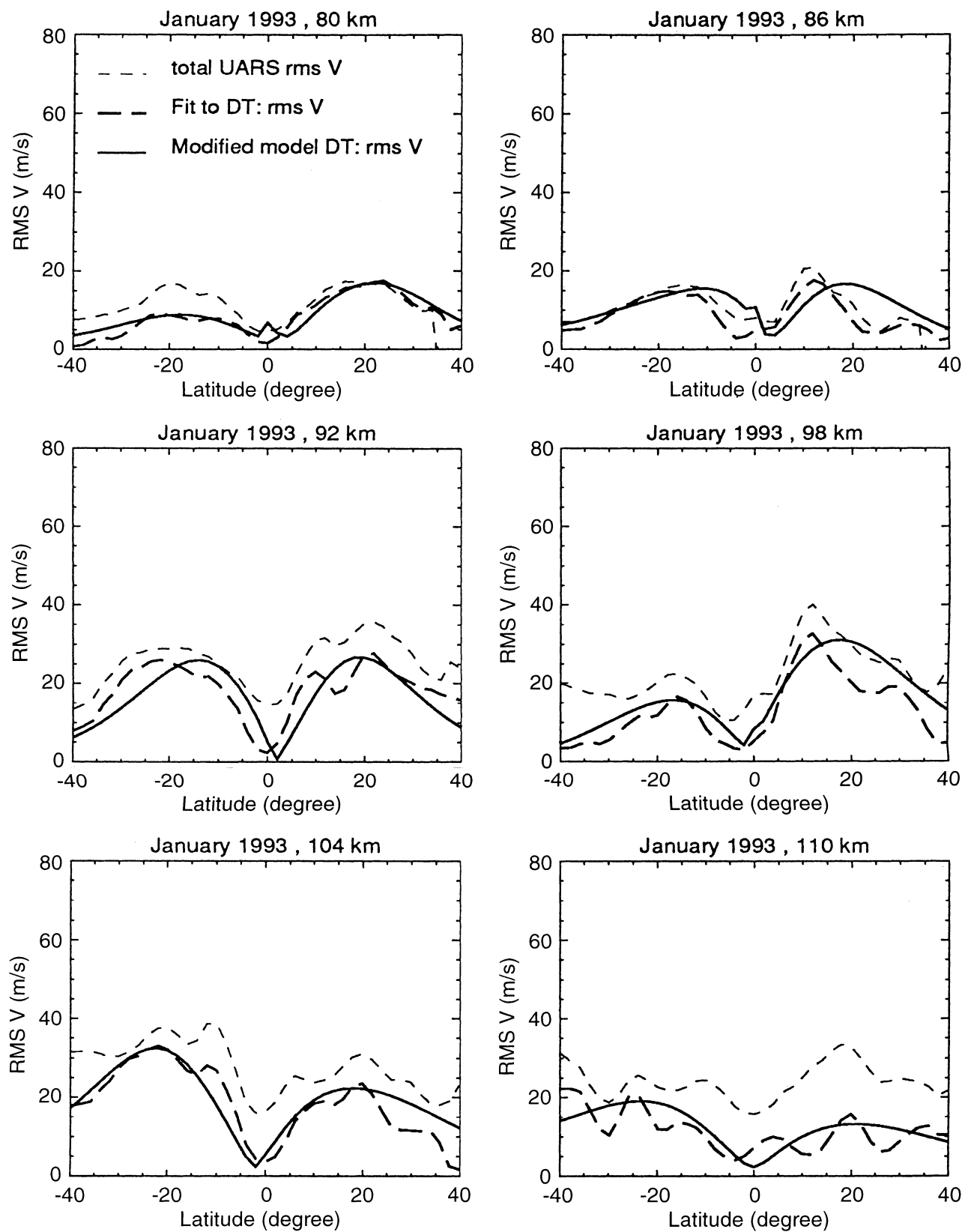

Fig. 4. As in Fig. 3, but for January 1993

two models is probably attributable to the different nature of the models (the SMLTM is a time-dependent nonlinear model, while the TMTM is a mechanistic linear tidal model).

Despite rather small discrepancies in the model/ model and model/measurement comparisons, we conclude that using the UARS meridional wind constraint in the low-latitudinal MLT region, the TMTM can closely reproduce the satellite observations and, in many basic features, follows the more comprehensive SMLTM simulation of the tides. Figure 6 illustrates the diurnal amplitude structures for January 1993. In comparison to the equinox amplitude structures, we see a much weaker diurnal tidal oscillation in the wind and temperature fields. The solstice amplitudes of the diurnal tide are approximately two times smaller than those at equinox. Due to the strong influence of other motions (mean flow, planetary waves and gravity waves) it is difficult to get reliable estimates of the diurnal zonal wind and temperature amplitudes using the LSF procedures, especially when the satellite data has only $8-12 \mathrm{~h}$ coverage. However, the decrease in the observed solstice amplitudes in the temperature fields around the equator $\left(12^{\circ} \mathrm{K}\right)$ and in the zonal winds is seen from the comparison of Figs. 6 and 5 (bottom rows).

In this sense, the estimates of the diurnal variation of the zonal winds and temperatures from the TMTM are a valuable product, since the derived zonal wind and temperature amplitudes are consistent with the meridional tidal winds observed by UARS, and the TMTM 

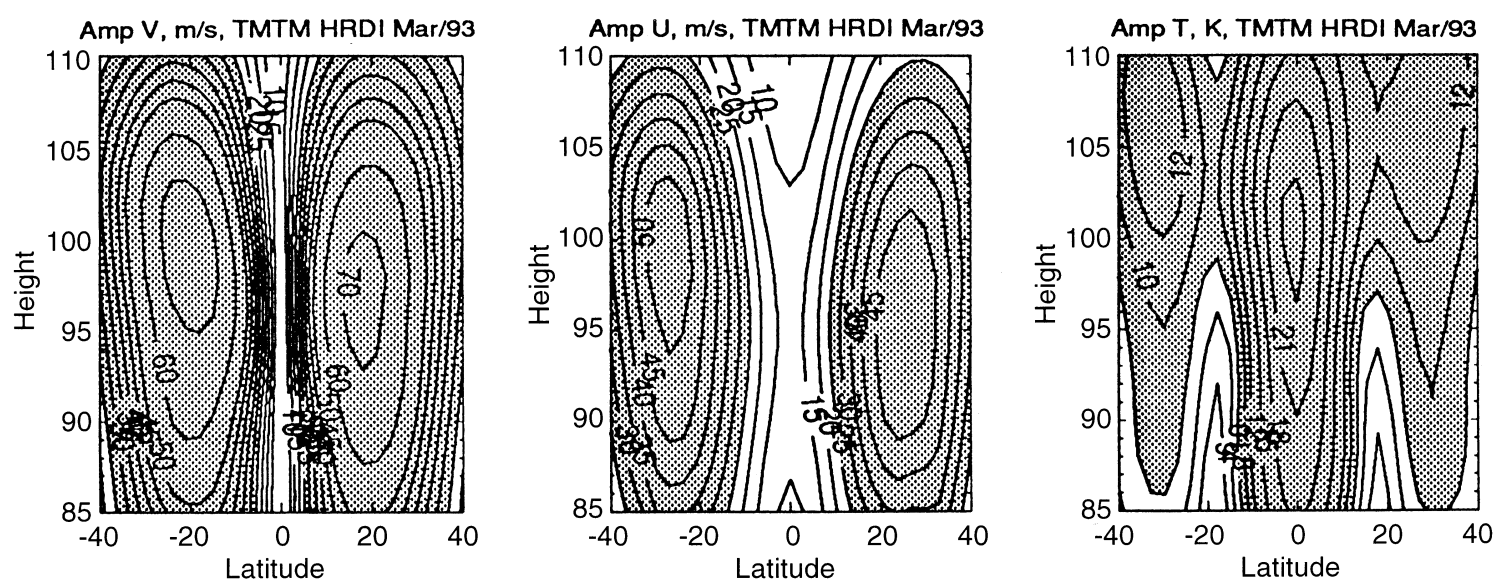

Amp V, m/s, TMTM WINDII+HRDI Mar/93 Amp U, m/s, TMTM WINDII+HRDI Mar/93
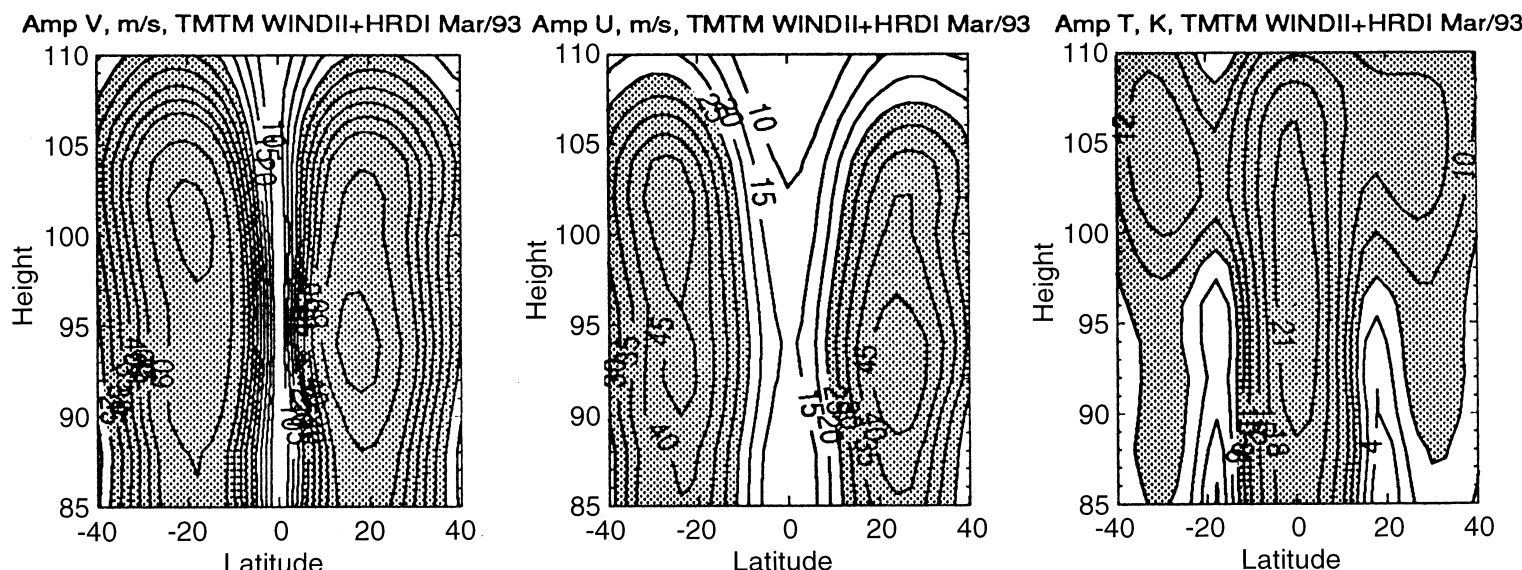

DT: Amp V, m/s, WINDII Mar 93

DT: Amp U, m/s, WINDII Mar $/ 93$
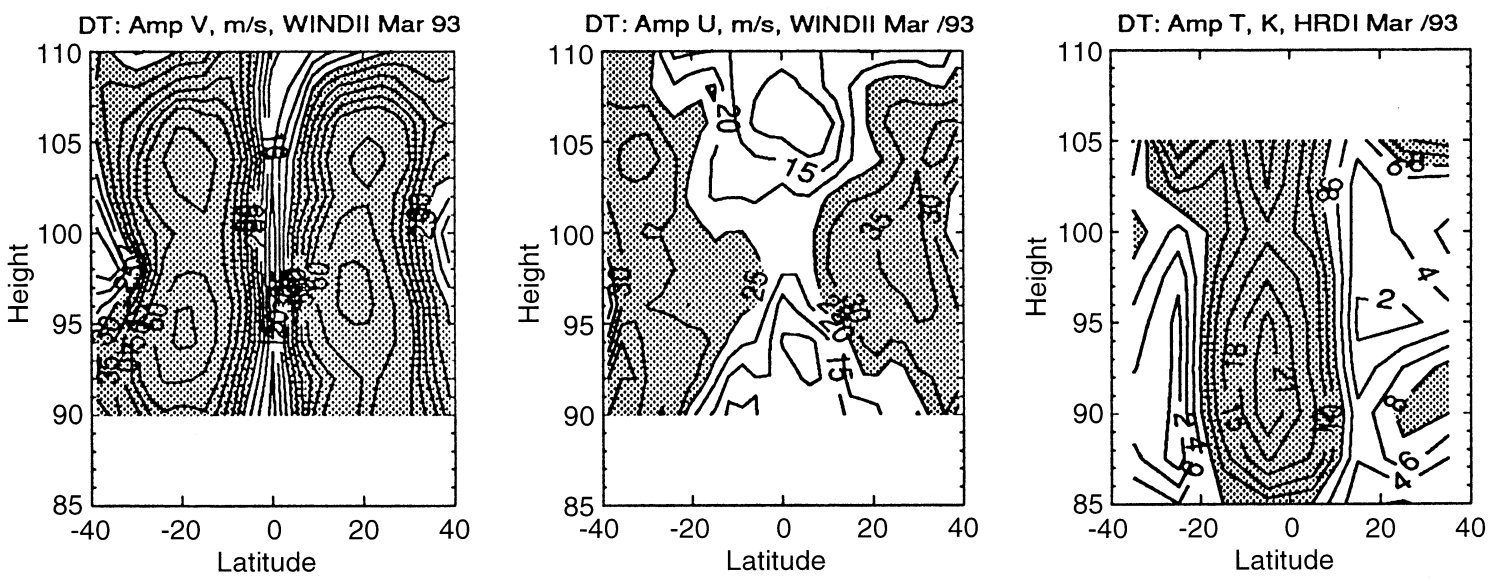

Fig. 5. The diurnal amplitude structures of zonal and meridional winds and temperatures for March 1993. First two rows are predictions generated by TMTM using different initial guesses for the iterative procedure. First two plots in the bottom row are the

diurnal amplitudes of the meridional and zonal components estimated from WINDII observations (McLandress et al., 1996a). Last plot in the third row is a least-squares fit to the HRDI temperatures

can be considered as an efficient estimator of the other tidal variables (through the tidal equations). Using these procedures, a first guess can be determined for the monthly mean satellite zonal winds if we remove the TMTM tides from the satellite wind observations. An example of this procedure for the zonal winds is presented in Fig. 7 (second row). The first row shows the TMTM results using the combined HRDI/WINDII meridional winds for March 1993 at 12 LT. There is very good agreement between the TMTM results and the observations in the region between $40^{\circ} \mathrm{S}$ and $40^{\circ} \mathrm{N}$ where the values for the atmospheric dissipation in the TMTM have been "tuned". It should be emphasized that these decompositions of the monthly mean UARS winds onto mean flow and tides on the basis TMTM results are a first approximation to atmospheric reality, because prescribed tidal forcings and background temperatures and winds are used in the TMTM simulations. 

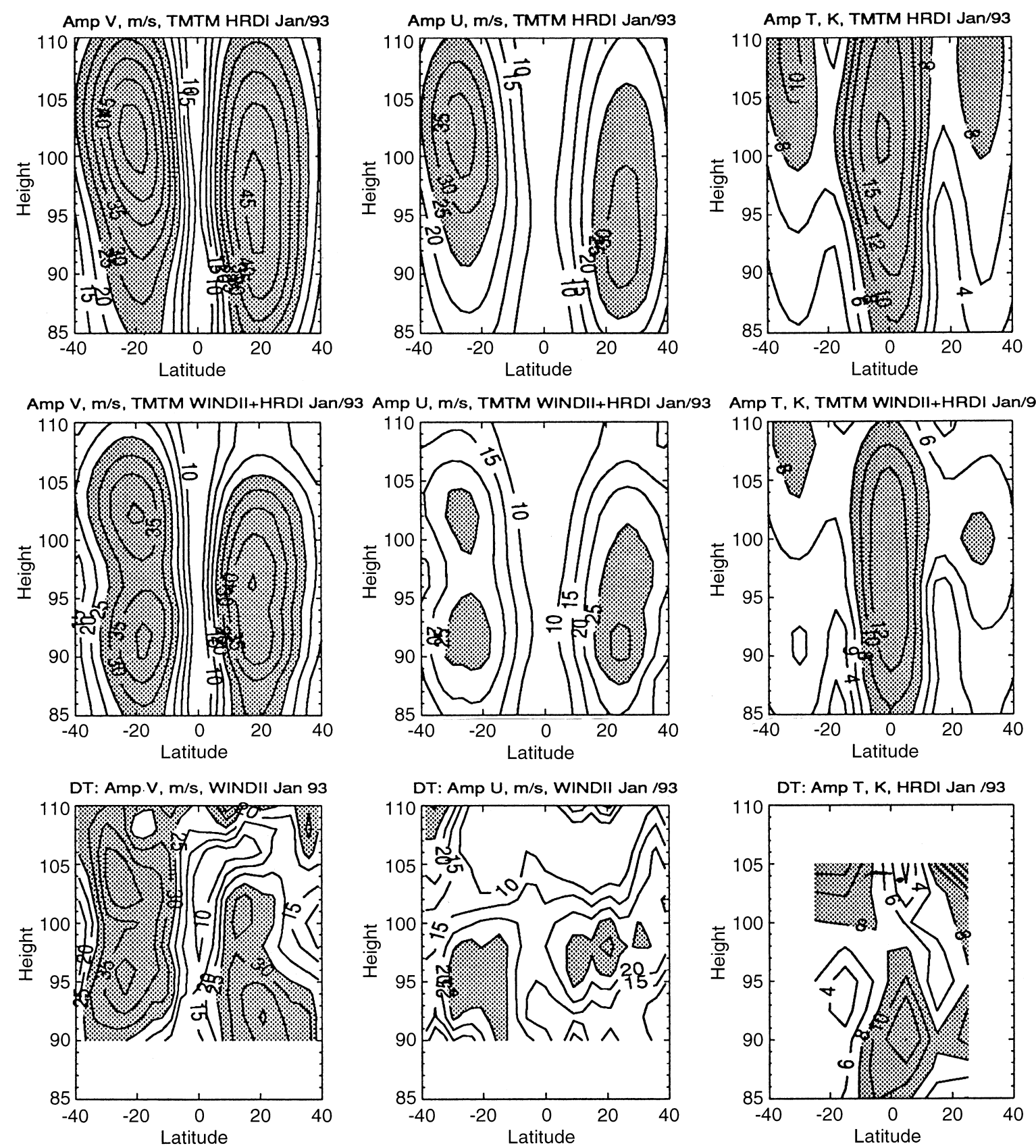

Fig. 6. As in Fig. 5, but for January 1993

It is interesting to note that the January diurnal amplitude profiles generated by the TMTM (second row) agree quite well with the SMLTM results for the diurnal temperature and wind amplitudes (Figs. 4-6, in Akmaev et al., 1997). To obtain the weak diurnal amplitudes for the solstice periods they use a $50 \%$ increase in the total gravity wave energy at low latitudes following the specific features of the gravity wave climatology in the lower atmosphere discussed by Allen and Vincent (1995). The conclusion of the SMLTM experiments is that the seasonal variation of the diurnal amplitudes appears to be controlled by observed variations of gravity wave forcing in the troposphere. To study these aspects, we run the TMTM for 12 months using only the 1992-1993 HRDI daytime observations of the meridional winds for tuning.

The seasonal changes of the diurnal wind amplitudes for different latitudes are illustrated in Fig. 8. The $20^{\circ} \mathrm{S}$ and $20^{\circ} \mathrm{N}$ results are shown in the first two rows, and the $35^{\circ} \mathrm{S}$ and $35^{\circ} \mathrm{N}$ results are shown in the last two rows. The first column of Fig. 8 is the initial guess for the TMTM, the last two columns are the zonal wind and the meridional wind amplitudes simulated by the TMTM. Comparison of the first two columns reveals that the TMTM procedure has a tendency to smooth the seasonal variation of amplitude below $80 \mathrm{~km}$ and above $105 \mathrm{~km}$, where the influence of seasonal changes in the specified tidal forcing and molecular dissipation is 

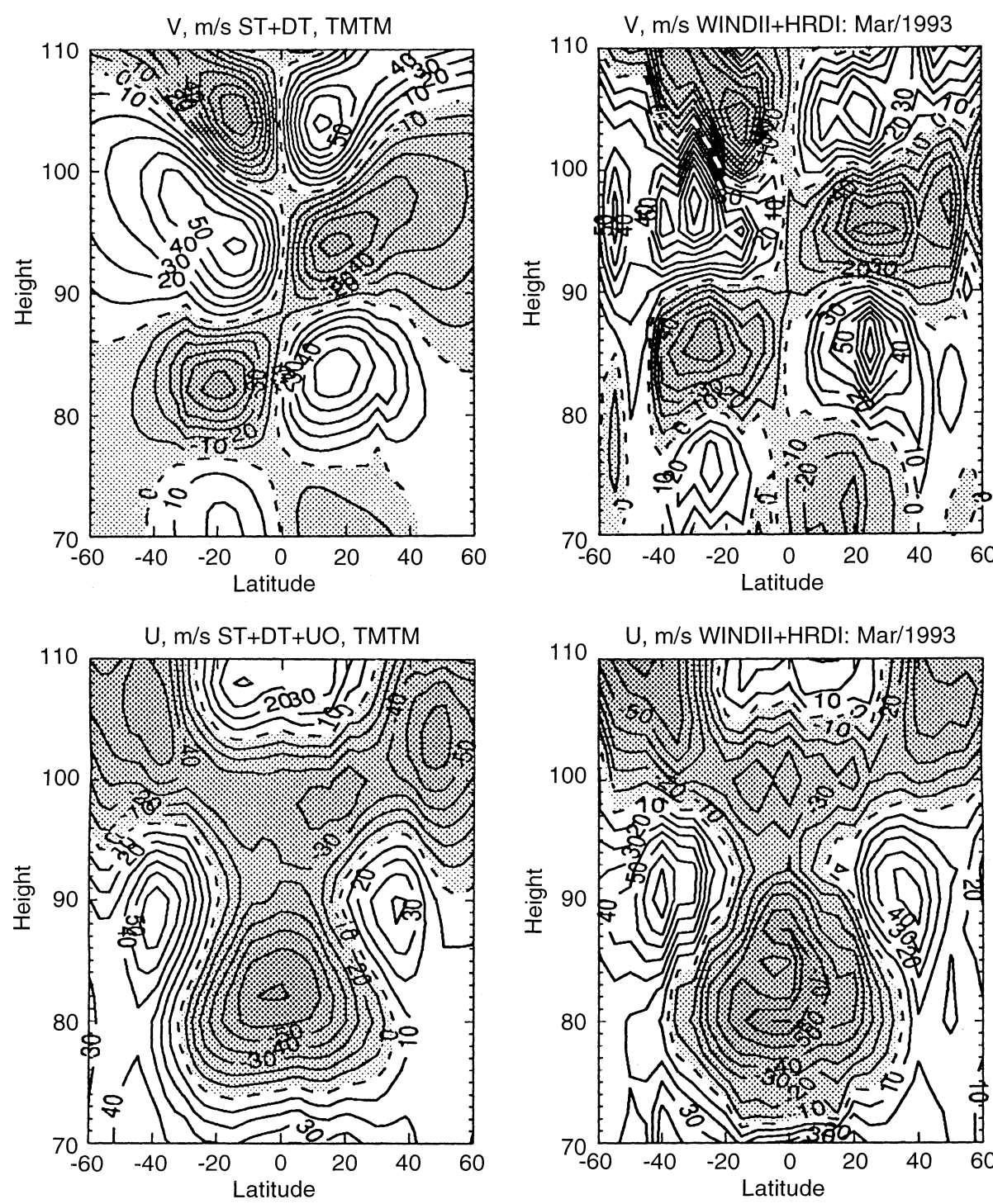

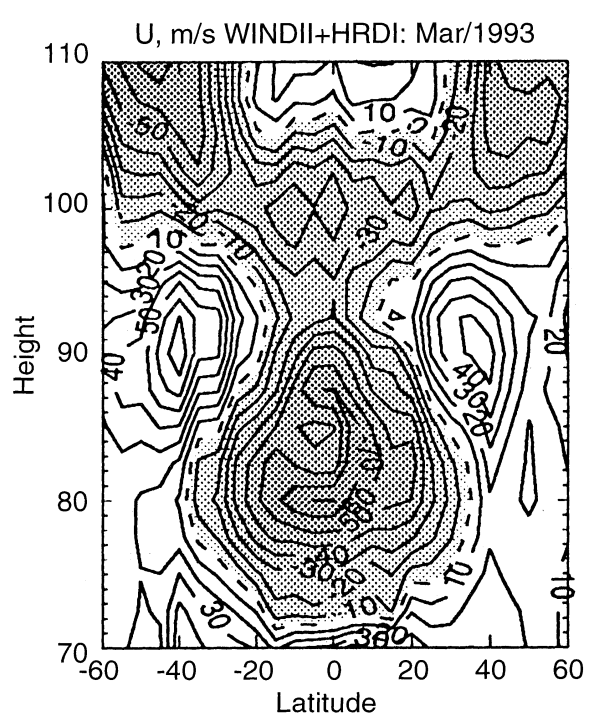

Fig. 7. Meridional and zonal winds predicted by tuned mechanistic tidal model results and HRDI/WINDII meridional and zonal wind observations in March 1993 at 12 LT. The mean zonal wind (not shown) is estimated by subtracting the predicted diurnal zonal wind patterns from the satellite observations. For simulation of the semidiurnal tides, the derived tidal dissipation from the diurnal TMTM simulation are used important. The summer local maxima in June and July between 90 and $100 \mathrm{~km}$ seems to be an artifact of our LSF procedures to HRDI data. To be more specific, we can compare our results with Figs. 13-15 from McLandress et al. (1996a), where the seasonal behavior of the diurnal tidal wind amplitudes has been obtained from the 1992-1993 WINDII observation for $20^{\circ} \mathrm{N}, 35^{\circ} \mathrm{N}$, and $35^{\circ} \mathrm{S}$. From these comparisons, we conclude that our concerns regarding the presence of spurious JuneJuly maxima in the northern hemisphere appear to be true, although in the southern hemisphere (Fig. 15 in McLandress et al., 1996a), we observe spreading of the high amplitude values from June to October in the zonal wind component. Our general impression from comparisons between WINDII estimates and TMTM predictions of the seasonal cycle of diurnal wind amplitudes (except June-July) is that the TMTM is in reasonable agreement with WINDII estimates between 90 and $110 \mathrm{~km}$. There are some fine features in the wind amplitude structures seen in the 24-h WINDII estimates which are not seen in the TMTM. We need to remember, however, that the TMTM uses only daytime
HRDI data as an initial guess, and that some smoothing was used in putting the first guess into the numerical model. The preceding results (Figs. 5 and 6) show that the TMTM can reproduce the double-peak structure wind amplitudes when the 24-h WINDII data is incorporated in the initial guess.

It is interesting to compare the obtained seasonal cycle of the HRDI diurnal tide amplitude to the seasonal diurnal tide climatology derived from MF radars. Some features of this comparison have been discussed in Khattatov et al. (1997a) for the Adelaide $\left(35^{\circ} \mathrm{S}\right)$, Kauai $\left(21^{\circ} \mathrm{N}\right)$, and Urbana $\left(44^{\circ} \mathrm{N}\right) \mathrm{MF}$ radars for 1992 meridional wind observations. The annual variability of the diurnal amplitudes at $90 \mathrm{~km}$ for the 1992 Adelaide and Kauai measurements and TMTM results is shown in Fig. 9. There is qualitative agreement between the seasonal evolution of the diurnal winds predicted by the radars and the TMTM results at $90 \mathrm{~km}$, except in winter Adelaide months. The Kauai tidal amplitudes are two times less than the TMTM estimates, although both results show similar annual behavior. Above $90 \mathrm{~km}$ the MF radar tidal amplitudes show a 


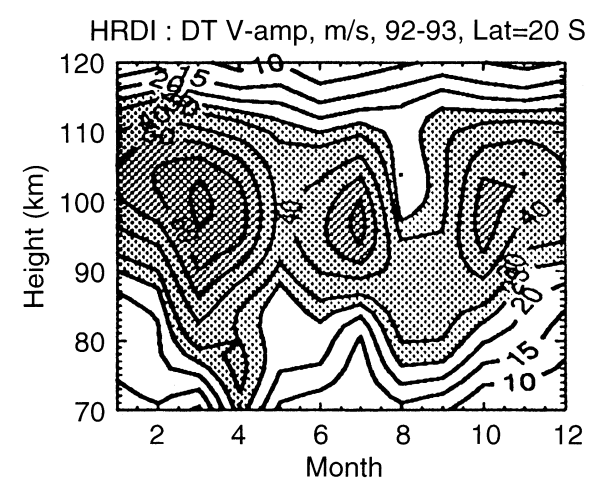

HRDI : DT V-amp, m/s, 92-93, Lat=20 N

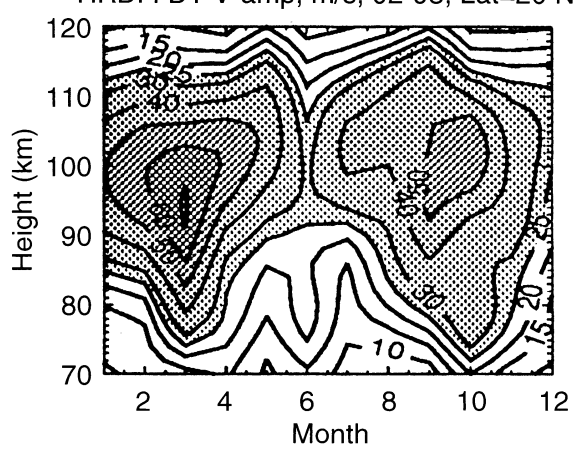

HRDI : DT V-amp, m/s, 92-93, Lat=35 S

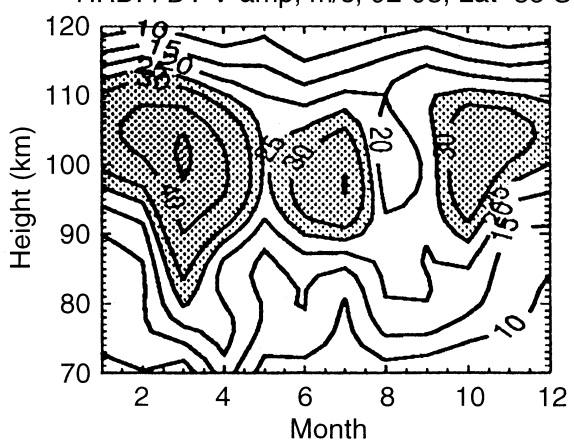

HRDI : DT V-amp, m/s, 92-93, Lat $=35 \mathrm{~N}$

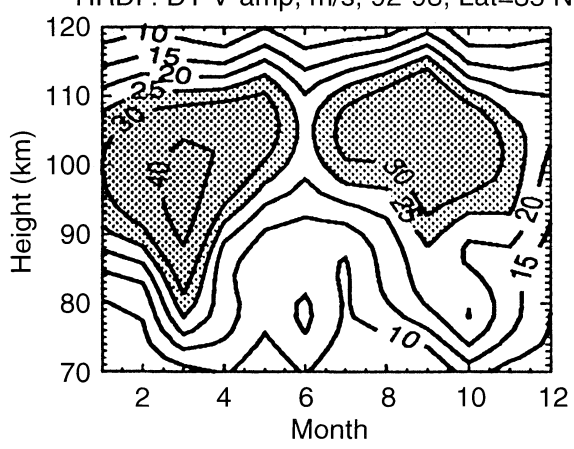

Fig. 8. Seasonal changes in the zonal and diurnal wind amplitudes as predicted by the TMTM at different latitudes as a function of altitude and month of year. First two rows are for $20 \mathrm{~S}$ and $20 \mathrm{~N}$; last two

marked decrease in their amplitudes with height during all months, while the UARS observations and TMTM results show a clear seasonal variation of tidal amplitudes (see Fig. 8). It is interesting to compare the seasonal changes in the differences of zonal and meridional phases (not shown). The TMTM phase differen-
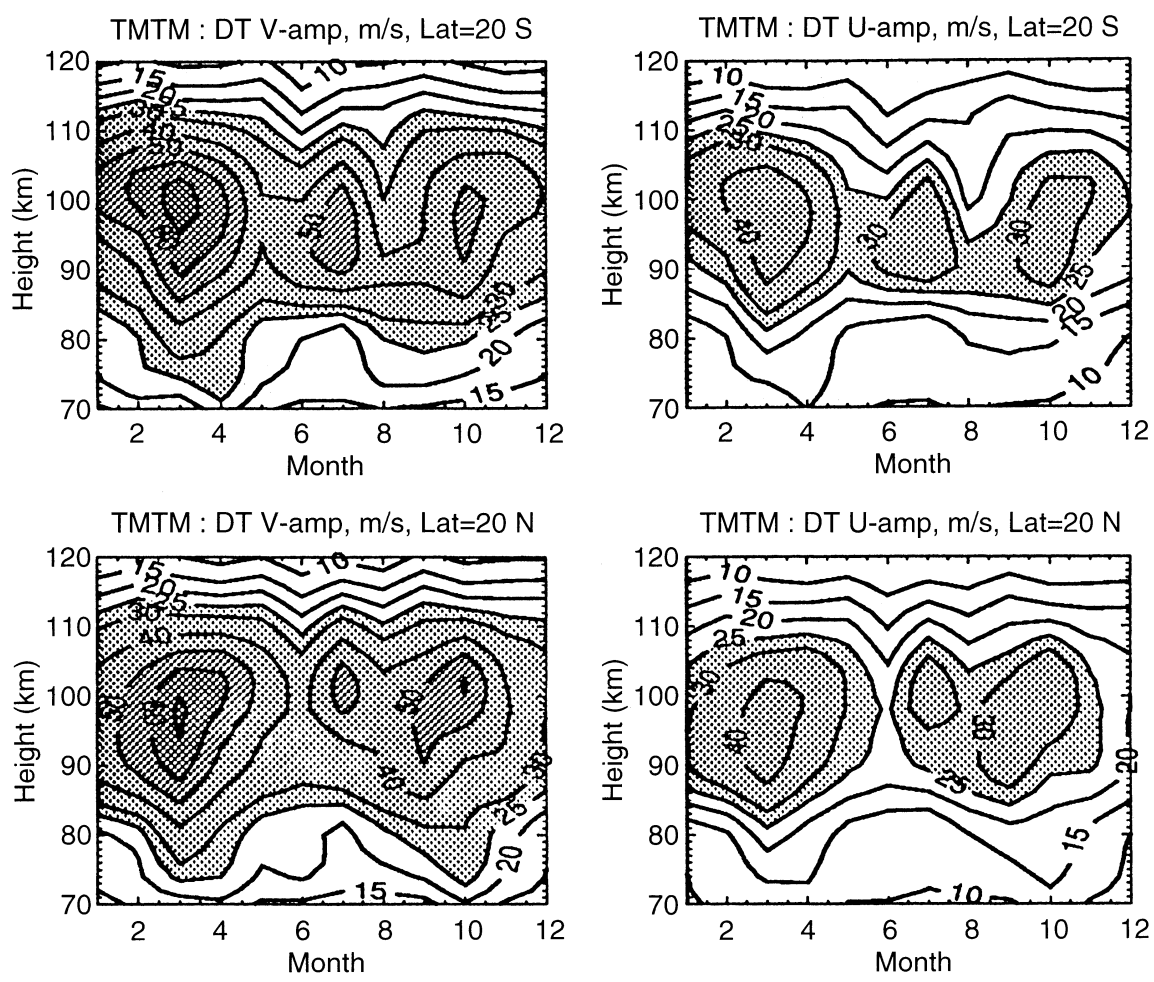

TMTM : DT U-amp, m/s, Lat=20 N

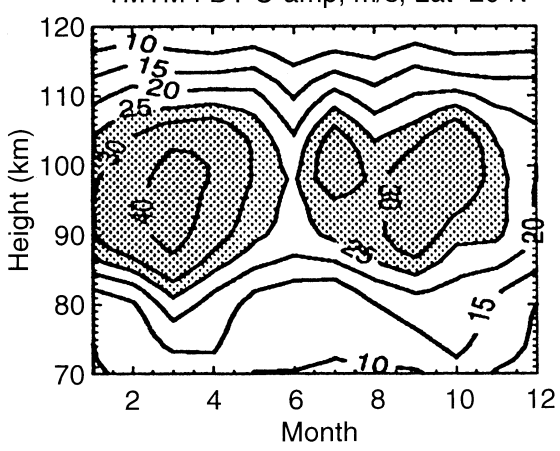

TMTM : DT U-amp, m/s, Lat=35 S

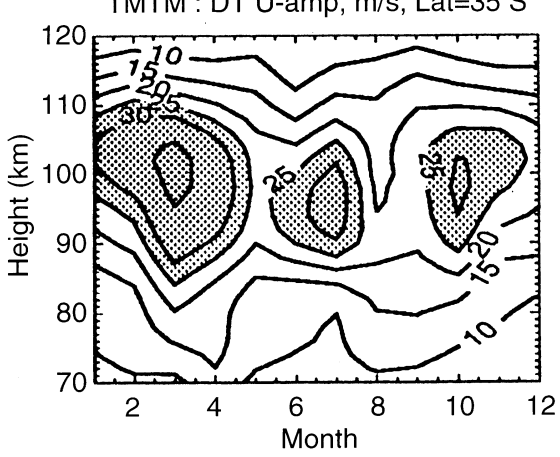

TMTM : DT U-amp, $\mathrm{m} / \mathrm{s}$, Lat $=35 \mathrm{~N}$

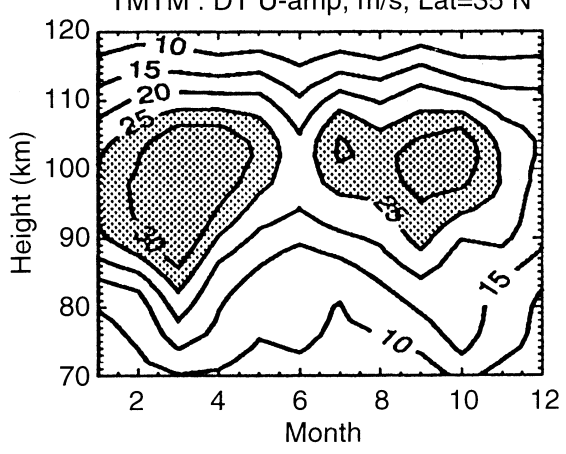

rows are for 355 and 35 N. First column is the initial guess used in the TMTM. Second and third columns are the meridional and zonal wind amplitudes generated by the TMTM procedures

ces do not show any significant seasonal variation and approximately equals $-6 \mathrm{~h}$ as predicted by the classical tidal equations. The radar phase differences show a significant deviation from the -6 -h classical phase lag during the winter months, when the gravity and planetary wave-tidal interaction appears to be important. 


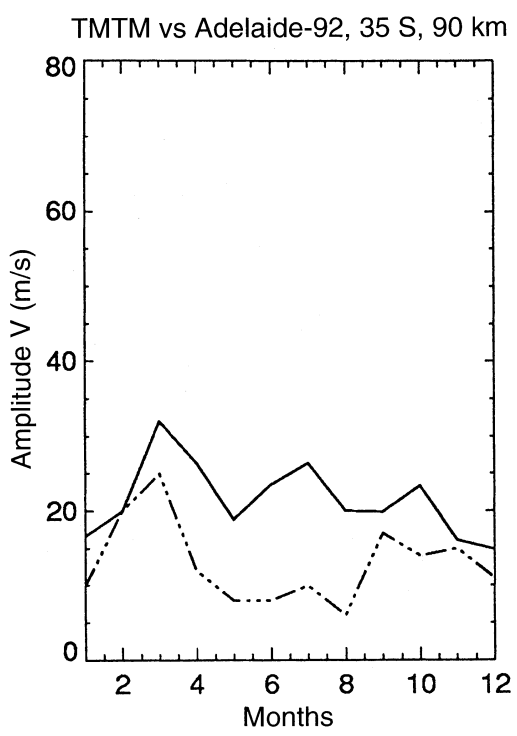

TMTM vs Hawaii-92, $21 \mathrm{~N}, 90$ km

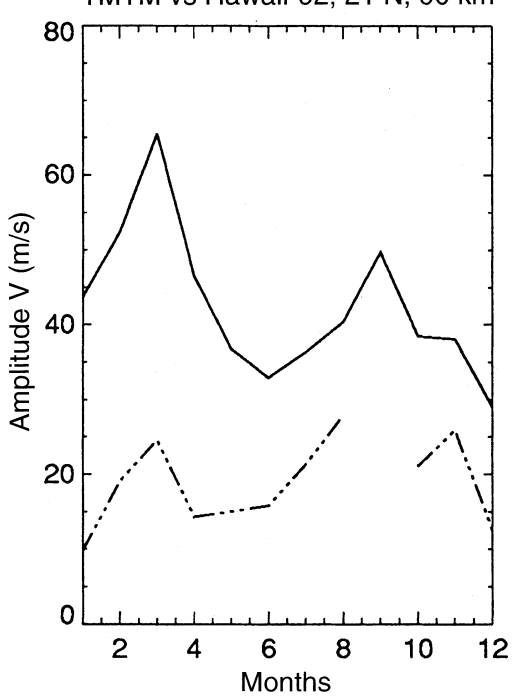

TMTM vs Adelaide-92, $35 \mathrm{~S}, 90 \mathrm{~km}$

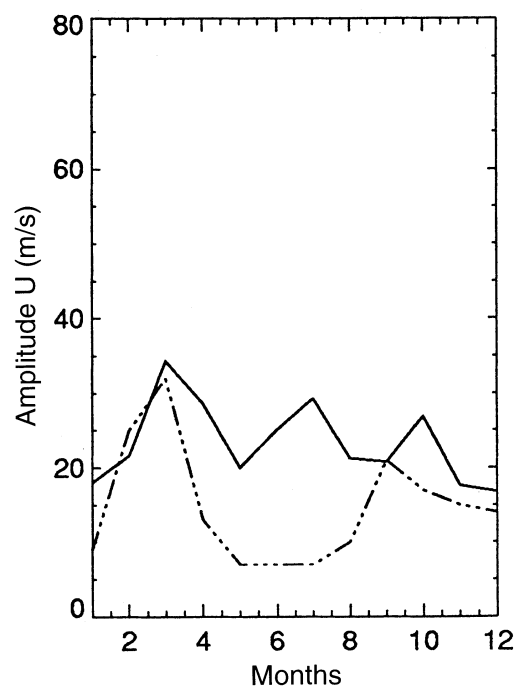

TMTM vs Hawaii-92, $21 \mathrm{~N}, 90$ km

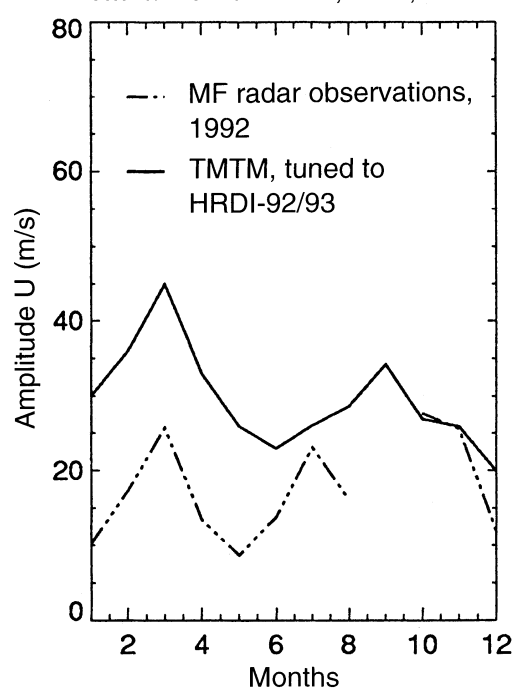

Fig. 9. Seasonal changes in the diurnal meridional and zonal winds predicted by TMTM and observed by the Adelaide $\mathrm{MF}$ radar $\left(35^{\circ} \mathrm{S}\right)$ and Kauai $\left(21^{\circ} \mathrm{N}\right)$ at $90 \mathrm{~km}$. First column is amplitudes of meridional wind component. Second column is amplitudes of zonal wind component. Dash-dotted lines correspond to the 1992 monthly averaged MF radar diurnal tides. Solid lines are for the diurnal wind amplitudes predicted by TMTM runs
Vincent et al. (1989) discussed the observed tidal asymmetries between the Adelaide $\mathrm{MF}$ radar $\left(35^{\circ} \mathrm{S}\right)$ and Kyoto meteor radar $\left(35^{\circ} \mathrm{N}\right)$ during $1983-1985$. The Adelaide observations show large diurnal amplitudes and are characterized by a propagating component with a relatively short vertical wavelength $(30-40 \mathrm{~km})$, whereas the diurnal oscillations at Kyoto have much weaker amplitudes and a longer wavelength. From the comparison of the two last rows of Fig. 8 ( $35^{\circ} \mathrm{S}$ and $35^{\circ} \mathrm{N}$ ) we see that the TMTM results based on HRDI observations also show the diurnal tide asymmetries that are indicated by the radar observations. These asymmetries below $100 \mathrm{~km}$ are clearly seen during the equinox periods (February-March-April and September-October) in the zonal and meridional components. Vincent et al. (1989) argued that the asymmetrical structures of the atmospheric dissipation might be a key point for the explanation of the observed tidal asymmetries at Adelaide and Kyoto.

Another product of the TMTM runs is the tidal dissipation. Figure 10 illustrates its seasonal changes for different latitudes $\left(35^{\circ} \mathrm{S}-35^{\circ} \mathrm{N}, \quad 20^{\circ} \mathrm{S}-20^{\circ} \mathrm{N}\right)$. Below $100 \mathrm{~km}$, a major component of the tidal dissipation is presumably the eddy diffusion generated by gravity wave breaking. We have some reservations about our predictions for the June-July dissipation because the local amplitude maxima in June and July above $90 \mathrm{~km}$ seems to be an artifact of our LSF procedures to HRDI data. That is why the contours for these months are shown in dashed lines, reflecting the linear interpolation between the May and August results. The basic features of the seasonal changes in the eddy dissipation can be related to the observed variance of the square of the diurnal amplitudes. We see very weak tidal damping in March-April at low latitudes during 1992-1993. Another period of weak tidal damping derived by the TMTM occurs in September-October-November. It should be noted that there is a different seasonal behavior of the $100 \mathrm{~m}^{2} / \mathrm{s}$ contour at $35^{\circ} \mathrm{S}$ and $35^{\circ} \mathrm{N}$. For instance, the calculated tidal dissipation over Kyoto $\left(35^{\circ} \mathrm{N}\right)$ does not show the large seasonal variance of the $100-\mathrm{m}^{2} / \mathrm{s}$ contour during the first 5 months of the year, 

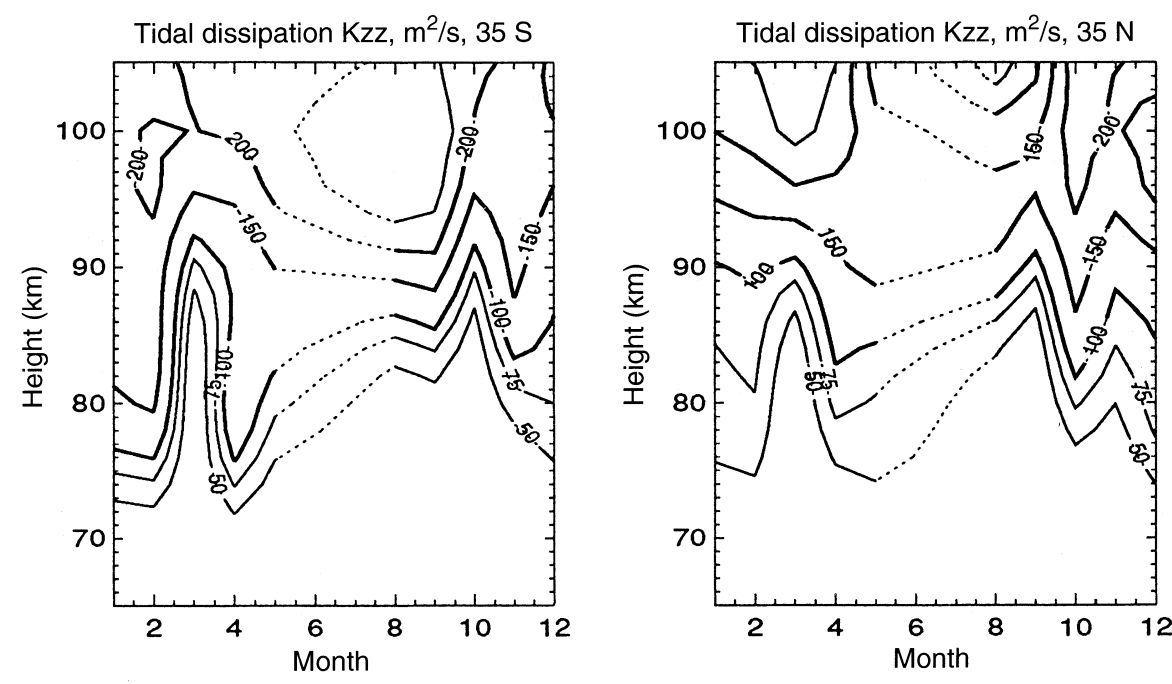

Tidal dissipation $\mathrm{Kzz}, \mathrm{m}^{2} / \mathrm{s}, 20 \mathrm{~S}$

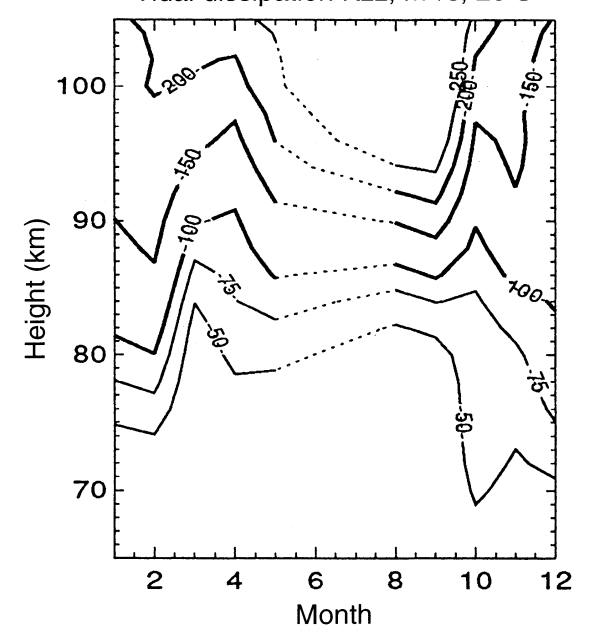

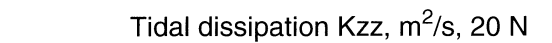

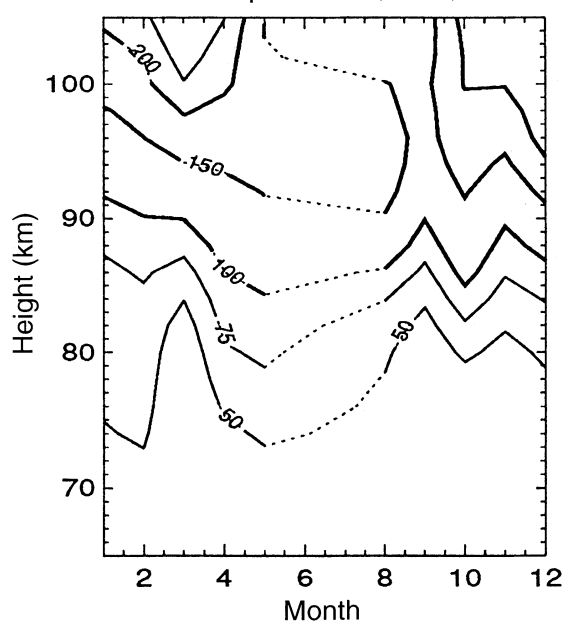

Fig. 10. Seasonal changes in the tidal dissipation from TMTM runs employing the 1992-1993 HRDI meridional wind for tuning. Latitudes roughly correspond to the locations of Adelaide $\left(35^{\circ} \mathrm{S}\right)$, Kyoto $\left(35^{\circ} \mathrm{N}\right)$, and Kauai $\left(21^{\circ} \mathrm{N}\right)$ while at Adelaide $\left(35^{\circ} \mathrm{S}\right)$, we see a significant contrast between the summer and spring behavior of the $100 \mathrm{~m}^{2} / \mathrm{s}$ contour. Some discussion of the sensitivity of the GWSM to differences in the tidal dissipation are discussed in Geller et al. (1997). In this respect, the atmospheric dissipation derived from the TMTM on the basis of the UARS measurements appears to be valuable observational constraint of the atmospheric dissipation in the low-mid-latitudes of the MLT (see also the discussion in Yudin et al., 1997). In future applications of the TMTM, the utilization of the 24-h WINDII data between 90 and $110 \mathrm{~km}$ will provide another powerful data set for deriving the seasonal cycle of tidal damping, especially for understanding the winter-summer contrasts in the northern and southern hemispheres. Based only on the HRDI winds, the TMTM predicts that above $100 \mathrm{~km}$ the winter tidal dissipation is much stronger than in the summer in both hemispheres (see also the discussion in Khattatov et al., 1997b). This prediction is consistent with another conclusion of Vincent et al. (1989) that the diurnal amplitudes observed by radars in summer tend to be larger than in winter.
It is interesting to compare the derived seasonal cycle of the tidal dissipation with the seasonal variability of vertical small-scale eddy diffusivity observed by the Kyoto MU radar from January 1986 to December 1988 (Fukao et al., 1994). Although the strength of the smallscale diffusivity is not directly comparable to the tidal dissipation, we argue that the seasonal changes in both diffusivities might be controlled by the variability of gravity waves, and have similar seasonal changes. During these 3 years, indeed, the Kyoto MU radar observed relatively weaker mesospheric turbulence during the equinox periods than in the winter-summer seasons below $80 \mathrm{~km}$. This semiannual turbulence variability observed by the MU radar with a minima in the equinoctial seasons seems to be an additional independent confirmation of weak tidal damping during the equinoxes derived by the TMTM from HRDI wind data.

\section{Summary and conclusions}

Numerical simulations of the diurnal and semidiurnal tides in the MLT region are presented using a tuned 
mechanistic tidal model (TMTM) that utilizes the meridional tidal winds observed by the Upper Atmosphere Research Satellite (UARS). A developed TMTM methodology, using a mechanistic tidal model in combination with UARS data, has been tested using independent geophysical data sets from HRDI (daytime) and WINDII (day- and nighttime) wind measurements.

On the basis of the TMTM simulations, it was shown that a decomposition of the UARS winds into a mean flow plus diurnal and semidiurnal tides is a reasonable first approximation that can be used to extract the tides and mean flow from monthly mean satellite wind composites between 80 and $110 \mathrm{~km}$.

Except during June and July of 1992-1993, a tuning of the tidal model parameters using only the HRDI diurnal fits does a good job for evaluating the migrating diurnal winds as seen from the comparison of the derived tidal amplitudes with the WINDII estimates (McLandress et al., 1996a). Comparisons between diurnal temperature amplitudes derived from HRDI observations and predicted by TMTM also show good agreement in the equatorial region between 85 and $105 \mathrm{~km}$. This means that UARS measurements of both temperature and winds are consistent with each other, indicating a coherent migrating diurnal tide.

UARS satellite observations of winds and temperatures reveal strong seasonal variations in diurnal amplitudes, with maxima at the equinox periods and minima at solstices. Such a semiannual seasonal cycle of the tidal amplitudes has been detected earlier by MF radars at middle and low latitudes of MLT, but the radar seasonal tidal variability is much less that what is seen in the satellite observations above $90 \mathrm{~km}$.

The TMTM simulations show that the seasonal variations in the derived tidal damping can reproduce these strong seasonal wind amplitude variations observed by UARS. The derived dissipation of the diurnal tide between $40^{\circ} \mathrm{S}$ and $40^{\circ} \mathrm{N}$ maximizes at higher altitudes, and is in fact smaller in value than what has been considered in tidal models before the availability of UARS data. There is also good agreement between TMTM and the Spectral Mesosphere/Lower Thermosphere Model simulations of the diurnal tide (Akmaev et al., 1997). To obtain the UARS-observed strong contrast between the equinox and solstice diurnal tide, Akmaev et al., (1997) use a 50\% increase in the gravity wave forcing at the model lower boundary during the solstice seasons. Thus the derived tidal dissipation by the TMTM methodology seems to be consistent with the results from the SMLTM and reflects the seasonal changes of mixing induced by the gravity wave breaking in the MLT region. Much of the latitudinal asymmetries of the diurnal tides observed by radars and UARS are probably attributable to the different seasonal behavior of tidal dissipation that reflects the latitude dependent gravity wave influence on the tides and other aspects of the circulation in MLT.

This present study can be viewed as a step toward assimilative analysis/interpretation of UARS wind and temperature observation in the MLT region. Utilization in this analysis of the 24-h WINDII wind data in the 90$110-\mathrm{km}$ region can improve (the TMTM derivation of tidal amplitudes and dissipation and help decomposition of the satellite monthly mean wind composites on mean flow and tidal components. The derived seasonal changes in tidal dissipation appear to be a useful product for other modeling studies, including the tidal effects on mean flow and simulation of the planetary wave damping in the MLT region.

Acknowledgements. This study is sponsored by NASA's UARS project.

Topical Editor F. Vial thanks A. K. Smith, R. W. Zurek for their help in evaluating this paper.

\section{Appendix}

Use of the wave energy equation to estimate dissipation for the TMTM

The local solar time averaged wave energy equation for linear oscillations in a viscid vertically stratified atmosphere can be written as follows:

$$
\begin{aligned}
\frac{\partial}{\partial t} E= & -\frac{\partial}{\partial z}\left[\overline{P^{\prime} W^{\prime}}+\bar{U} \bar{\varrho} \overline{U^{\prime} W^{\prime}}\right] \\
& +\frac{1}{2} \frac{\partial}{\partial z}\left[K_{z} \bar{\varrho} \frac{\partial\left(\overline{U^{\prime 2}}+\overline{V^{\prime 2}}\right)}{\partial z}+\frac{g^{2}}{N^{2}} K_{t} \bar{\varrho} \frac{\partial \overline{\left(T^{\prime} / T_{o}\right)^{2}}}{\partial z}\right] \\
& -\frac{1}{a \cos \theta} \frac{\partial}{\partial \theta}\left[\overline{P^{\prime} V^{\prime}} \cos \theta\right]-\bar{U} \frac{\partial}{\partial z}\left[\bar{\varrho} \overline{U^{\prime} W^{\prime}}\right] \\
& -K_{z} \bar{\varrho}\left[\overline{\left(\frac{\partial U^{\prime}}{\partial z}\right)^{2}}+\overline{\left(\frac{\partial V^{\prime}}{\partial z}\right)^{2}}\right]-K_{t} \bar{\varrho} \frac{g^{2}}{N^{2}}\left[\overline{\left(\frac{\partial T^{\prime} / T_{o}}{\partial z}\right)^{2}}\right]
\end{aligned}
$$

For simplicity, we do not consider (in the derivation of Eq. A1) the latitude dependence of the background fields in the tidal equations, and the internal tidal forcing terms are also omitted. There is no limitation, in principle, to include the afore mentioned terms and effects. Standard notation is used in Eq. A1 for the independent variables and constants: $z$ - height; $t$ - time; $\theta$ - latitude; $a$ - radius of Earth; $g$ - gravity acceleration; $R$ - gas constant. The other variables in Eq. A1 have the following meaning: $U, V, W$ are eastward, northward, and vertical wind velocities; $\varrho, P, T$ are density, pressure, and temperature; $E$ is the total wave energy; $K_{t}, K_{z}$ are the vertical thermal conductivity and momentum diffusion coefficients; $N$ is the Brent-Väisälä frequency; $H=R T / g$. The overbar denotes local solar time averaging. Primed variables are wave oscillations.

If we assume that the wave variables and zonally averaged background fields are known (e.g., from observations), we can use Eq. A1 as a tool for the calculation of the $K_{z}$ and $K_{t}$ that give rise to the wave damping. Defining the Prandtl number $\mathrm{Pr}$ as the ratio between $K_{z}$ and $K_{t}$ and rewriting Eq. A1, we obtain the following first-order differential equation for $K_{z}$ :

$A \frac{\partial}{\partial z} K_{z}+B K_{z}=G$ 
where the $A, B$ coefficients and $G$ on the right side of Eq. A2 are expressed in terms of the wave variables, the zonally averaged wind and temperature, and the Prandtl number. Equation A2 can be solved by standard numerical methods for steady-state waves $(E(t)=$ const.) with a single boundary condition. For tidal applications it is convenient to specify the upper boundary condition because the molecular viscosity is considered to be a well-known model parameter. The numerical solution of Eq. A2 in the MLT region is not very sensitive to the specification of the upper boundary condition above $130 \mathrm{~km}$. The accuracy of the numerical solution of Eq. A2 can be easily tested using the output of a mechanistic tidal model.

\section{References}

Akmaev, R. A., V. A. Yudin, and D. A. Ortland, SMLTM simulations of the diurnal tide: comparison with UARS observation, Ann. Geophysicae, 15, this issue, 1997.

Allen, S. J., and R. A. Vincent, Gravity wave activity in the lower atmosphere: seasonal and latitudinal variations, J. Geophys. Res., 100, 1327-1350, 1995.

Burrage, M. D., M. E. Hagan, W. R. Skinner, D. L. Wu, and P. B. Hays, Long-term variability in the solar diurnal tide observed by HRDI and simulated by GSWM, Geophys. Res. Lett., 22, 2641-2644, 1995a.

Burrage, M. D., D. L. Wu, W. R. Skinner, and P. B. Hays, Latitude and seasonal dependence of the semidiurnal tide observed by the high-resolution Doppler imager, J. Geophys. Res., 100, 11313-11321, 1995b

Burrage, M. D., W. R. Skinner, D. A. Gell, P. B. Hays, A. R Marshall, D. A. Ortland, A. H. Manson, S. J. Franke, D. C. Fritts, P. Hoffman, C. McLandress, R. Nicijewski, F. J. Schmidlin, G. G. Shepherd, W. Singer, T. Tsuda, and R. A. Vincent, Validation of mesosphere and lower thermosphere winds from the high-resolution Doppler imager on UARS, $J$. Geophys. Res., 101, 10365-10392, 1996.

Crary, D. J., and J. M. Forbes, On the extraction of tidal information from measurements covering a fraction of day, Geophys. Res. Lett., 10, 580-582, 1982.

Forbes, J. M., and F. Vial, Semidiurnal tidal climatology of the E region, J. Geophys. Res., 96, 1147-1157, 1991

Forbes, J. M., M. Kilpatricjk, D. C. Fritts, A. H. Manson, and R. A. Vincent, Zonal mean and tidal dynamics from space: an empirical examination of aliasing and sampling issues, Proc Work Wind observations in the middle atmosphere, 15/18 November 1994, CNES-HQ, Paris.

Fritts, D. C., and J. R. Isler, Mean motions and tidal and two-day structure and variability in the mesosphere and lower thermosphere over Hawaii, J. Atmos. Sci., 51, 2145-2163, 1994.

Froidevaux, L., W. R. Read, T. A. Lungu, R. E. Cofield, E. F. Fishbein, D. A. Flower, R. F. Jarnot, B. P. Ridenoure, Z. Shippony, J. W. Waters, J. J. Margitan, I. S. McDermid, R. A. Stachnik, G. E. Peckman, G. Braathen, T. Deshler, J. Fishman, D. J. Hofmann, and S. J. Oltmans, Validation of UARS Microwave Limb Sounder ozone measurements, J. Geophys. Res., 101, 10017-10060, 1996.

Fukao, S., M. D. Yamanaka, N. Ao, W. K. Hocking, T. Sato, M. Yamamoto, T. Nakamura, T. Tsuda, and S. Kato, Seasonal variability of vertical eddy diffusivity in the middle atmosphere 1. Three-year observations by the middle and upper atmosphere radar, J. Geophys. Res., 99, 18973-18987, 1994.

Geller, M. A., V. A. Yudin, B. V. Khattatov, and M. E. Hagan. Modeling the diurnal tide with dissipation derived from UARS/ HRDI measurements, Ann. Geophysicae, 15, this issue, 1997.
Grose, W., and J. Gille (eds.), Upper-Atmosphere Research Satellite validation workshop III Report: temperature and constituents validation, NASA Conference Publ., CP-3317, 1996.

Hagan, M. E., J. M. Forbes, and F. Vial, On modeling migrating solar tides, Geophys. Res. Lett., 22, 893-896, 1995.

Hagan, M. E., C. McLandress, and J. M. Forbes, Diurnal tidal variability in the upper mesosphere and lower thermosphere, Ann. Geophysicae, 15, this issue, 1997.

Hays, P. B., V. J. Albreau, M. E. Dobbs, D. A. Gell, H. J. Grassl, and W. R. Skinner, The high resolution Doppler imager on the Upper-Atmospheric Research Satellite, J. Geophys. Res., 98, 10713-10723, 1993

Hays, P. B., D. L Wu, M. D. Burrage, D. A. Gell, H. J. Grassl, R. S. Lieberman, A. R. Marshall, Y. T. Morton, D. A. Ortland, and W. R. Skinner, Observations of the diurnal tides from space, $J$. Atmos. Sci., 51, 3077-3093, 1994

Hedin, A. E., Extension of the MSIS thermosphere model into the middle and lower thermosphere, J. Geophys. Res., 96, 11591172, 1991.

Hedin, A. E., E. L. Fleming, A. H. Manson, F. J. Schmidlin, S. K. Avery, R. R. Clark, S. J. Franke, G. J. Fraser, T. Tsuda, F. Vial, and R. A. Vincent, Empirical wind model for the middle and lower atmosphere, part 1, NASA Tech Memo. NASA TM104581, 1993.

Khattatov, B. V., M. A. Geller, V. A. Yudin, P. B. Hays, W. R. Skinner, M. D. Burrage, S. J. Franke, D. C. Fritts, J. R. Isler, A, H. Manson, C. E. Meek, W. Singer, P. Hoffman, and R. A. Vincent, Dynamics of the mesosphere and lower thermosphere as seen by MF radars and by HRDI/UARS, J. Geophys. Res., 101, 10333-10404, 1996.

Khattatov, B. V., M. A. Geller, V. A. Yudin, P. B. Hays, and R. A. Vincent, Diurnal tide as seen by HRDI/UARS Part 1: monthly mean meridional winds, J. Geophys. Res., 101, 4405-4422, 1997a.

Khattatov, B. V., V. A. Yudin, M. A. Geller, and P. B. Hays, Diurnal tide as seen by HRDI/UARS Part 2: monthly mean mean zonal and vertical winds temperature and atmospheric dissipation, J. Geophys. Res., 101, 4423-4435, $1997 \mathrm{~b}$.

McLandress, C., G. G. Shepherd, and B. H. Solheim, Satellite observations of thermospheric tides: results from the Wind Imaging Interferometer on UARS, J. Geophys. Res., 101, 40934114, 1996a.

McLandress, C., G. G. Shepherd, B. H. Solheim, M. D. Burrage, P. B. Hays, and W.R Skinner, Combined mesosphere/thermosphere winds using WINDII and HRDI data from the Upper Atmosphere Research Satellite, J. Geophys. Res., 101, 1044110453, $1996 \mathrm{~b}$.

Ortland, D. A., W. R. Skinner, R. S. Lieberman, and P. B. Hays, Retrieval and validation of mesospheric temperatures from HRDI measurements, Worksh UARS dynamics working group meeting, October 31-November 2, 1995, Toronto, 1995.

Ricaud, P., de La Noe, B. J. Connor, L. Froidevaux, J. W. Waters, R. S. Harwood, I. A. MacKenzie, and G. E. Peckman, Diurnal variabiliy of mesospheric ozone as measured by the UARS microwave limb sounder instrument: theoretical and groundbased validations, J. Geophys. Res., 101, 10077-10089, 1996.

Shepherd, G. G., G. Thuillier, W. A. Gault, B. H Solheim, C. Hersom, J. M. Alunni, J. F. Brun, S. Brune, Charlot, L. L. Cogger, D. L. Desaulniers, W. F. J. Evans, R. L. P. Gattinger, F. Girod, D. Harvie, R. H. Hum, D. J. W Kendall, E. J. Llewellyn, R. P Lowe, J. Ohrt, F. Pasternak, O. Peillet, I. Powell, Y. Rochon, W. E. Ward, R. H. Weins, and J. Wimperis, WINDII: the Wind Imaging Interferometer on the Upper Atmosphere Research Satellite, J. Geophys. Res., 98, 10725-10750, 1993.

Vincent R. A., T. Tsuda, and S. Kato, Asymmetries in mesospheric tidal structures, J. Atmos. Terr. Phys., 51, 606-616, 1989.

Yudin, V. A., M. A. Geller, and B. V. Khattatov, Estimate of atmospheric dissipation derived from UARS/HRDI measurements, in Gravity wave processes and their parameterization in global climate models, Hamilton (ed.), Springer, Berlin, Heidelberg, New York. 187-197, 1997. 